\title{
Transient bioimpedance monitoring of mechanotransduction in artificial tissue during indentation
}

\author{
David Cheneler ${ }^{1,2,5}$, James Bowen ${ }^{3}$ and Georgia Kaklamani ${ }^{3,4}$ \\ 1. Department of Engineering, Lancaster University, Lancaster, UK \\ 2. School of Mechanical Engineering, The University of Birmingham, Edgbaston, UK \\ 3. School of Chemical Engineering, The University of Birmingham, Edgbaston, UK \\ 4. Institute of Electronic Structure and Laser (I.E.S.L.), Foundation for Research \& Technology-Hellas (FORTH), 711 10 Heraklion, Crete, Greece. \\ 5. E-mail any correspondence to: d.cheneler@lancaster.ac.uk
}

\begin{abstract}
Mechanotransduction is of fundamental importance in cell physiology, facilitating sensing in touch and hearing as well as tissue development and wound healing. This study used an impedance sensor to monitor the effective resistance and permittivity of artificial tissues, alginate hydrogel with encapsulated fibroblasts, which were kept viable through the use of a bespoke microfluidic system. The observed transient impedance responses upon the application of identical compressive normal loads differed between acellular hydrogels and hydrogels in which fibroblasts were encapsulated. These differences resulted from changes in the conductivity and permeability of the hydrogel due to the presence of the encapsulated fibroblasts, and transient changes in ion concentrations due to mechanotransduction effects.
\end{abstract}

Keywords: Bioimpedance, mechanotransduction, restitution, cells, artificial skin, tissue engineering

\section{Introduction}

Most, if not all, cell types are sensitive to mechanical stimuli [1, 2]. This is the result of the existence of mechanosensitive ion channels within the cell membrane [1]. The ion channels are comprised of proteins that are structured in such a way as to permit gating, in which the protein opens in a pore-like manner when activated by mechanical stimuli, such as tension or shear stress, acting on the membrane $[1,3]$. In this way, the channels vary the permeability of ions through the cell membrane. The ion flux caused by the mechanical stimuli is known as mechanotransduction [1].

Mechanotransduction is of fundamental significance in cell physiology besides the obvious application in facilitating sensing in specialized mechanoreceptors involved in touch, such as Pacinian corpuscles, Meissner's corpuscles, Merkel's discs and Ruffini endings found in glabrous skin [3], and hearing, such as hair cells in the cochlea [5]. In particular, mechanotransduction is involved in many important cell-regulated processes in tissues such as the growth of bone and muscle [6, 7], the development of blood vessels [8] and wound healing [9, 10]. Despite their importance, force-induced signaling pathways, and hence the science behind mechanotransduction, is still poorly understood $[11,12]$.

The main methods for measuring the electrophysiological properties of cells can be broadly divided into electrode based and optical techniques [13, 14]. For intracellular measurements, which involves measuring the electric potential across a cell membrane, a sharp microelectrode can be inserted into the cell and either voltage or current clamp techniques applied [15]. However, a more common method, the patch-clamp technique [13, 16], uses a pipette or microfabricated aperture into which a small section of the cell membrane (the 'patch') is drawn by way of an applied suction. The pipette is filled with an ionic solution and contains a single electrode to record currents through either individual ion channels or over the entire cell membrane. The whole-cell patch-clamp technique [16] requires a larger suction to be applied so that the membrane is ruptured. This ensures better access to the electrical properties inside the cell but, as the pipette is filled with an ionic solution, these properties will change as the contents of the cell become diluted. Sharp microelectrodes have also been employed for extracellular experiments [17]. These experiments, which may be performed in vivo or in vitro, involve an electrode being placed next to a cell, usually a neuron or muscle cell, and the local potential measured.

Both sharp electrode and patch-clamp techniques have the disadvantage of only being able to measure the electrical properties at a single location, whereas mechanotransduction can result in a spatial distribution of ion flux [18]. Optical methods overcome this by using fluorescing proteins or dyes which emit light in response to the local electrical or chemical activity that have been introduced into the tissue sample. The emitted light then permits observation of the spatial distribution of the ion flux [19]. This technique is, of course, limited to tissues with suitable optical properties.

The main issue with using these techniques to monitor the effects of mechanotransduction is that they in general require very thin tissue samples, cellular monolayers or even just single cells [20, 21]. However, it has recently been confirmed that the extracellular matrix (ECM) plays a 
key role in mechanotransduction $[11,22]$. It has been known for some time that the ECM serves as a tissue scaffold and a substrate for cell anchorage and hence guides cell migration and has other roles in tissue morphogenesis $[21,23]$. However, the ECM also transmits signals to the cells via electro-chemo-mechanical stresses [3] and hence influences most of the cells behavior including proliferation, differentiation and apoptosis [24]. This is because the ECM is connected to the intracellular cytoskeleton via transmembrane receptors, such as integrin, which can transmit forces $[25,26]$. This means that cells can actively react to varying external loads by changing the manner to which it attaches to the extracellular matrix, its cytoskeleton and transduce mechanical stress into electrochemical signals $[11,12]$. It is important to note that mechano-transduction does not just happen at adhesion sites, but can also occur due to stresses, such as shear stresses, at the cell membrane or single proteins acting as a mechanosensor [27].

One method that has recently shown potential for monitoring cellular responses in bulk tissues is bioimpedance or electrochemical impedance spectroscopy [28]. Using this technique, Qui et al. [29] monitored the development of adhesion in a layer of cells to the substrate by conducting a frequency sweep from $20 \mathrm{~Hz}$ to $200 \mathrm{kHz}$ every 10 minutes over a 20 hour period of cell culture and managed to relate the change in impedance to the decrease in cell-substrate distance and hence the increase in adhesion. Dodde et al. [30] used bioimpedance measurements to determine the change in electrical properties of non-viable porcine spleen tissue whilst under compression and noted the change in impedance could be due to cell damage or bulk water loss, but it was unclear as to which. In a similar experiment, Belmont et al. [31] monitored the impedance of tofu under compression as a tissue-mimic. It was assumed the impedance was frequency independent in the range of 1-300 kHz. Instead it was noted that the impedance depended on the strain. Again this was largely attributed to water loss. Nam et al. [32] monitored the change in impedance in viable zebra fish embryos, used as a test model of a cellular organism, and noted the amplitude of the impedance changed transiently under the influence of constant loads. In particular it was noted that the there was a delay in the change of amplitude of about 200 seconds after the load was applied. The exact mechanism for the change is not known, however forceinduced ionic movement through the pore canals in the chorion around the embryo was suggested [32].

In this paper, the effects of mechanotransduction are explored using viable artificial tissue-engineered skin in the form of an alginate encapsulated fibroblast. The artificial skin, which is considered to be a model system, is kept viable via a bespoke microfluidic system with integrated coplanar impedance sensors. Accurate normal loads are applied to the exposed surface of the artificial skin via indentation at small and large strains and the impedance monitored in real-time at a fixed single frequency. The fabrication of the microfluidic system and impedance sensors is described. The electrical properties of the artificial skin are related to the measured effective resistance and capacitance using conformal mapping. Differences in the transient impedance response during indentation between acellular and cellular samples are observed, suggesting possible mechanotransduction effects.

\section{Materials and methods}

\section{Experimental setup}

The transient bioimpedance of artificial skin was measured using a bioimpedance sensor integrated into a microfluidic system. The microfluidic system developed has several components (see Fig. 1). The substrate forms the base of the device and contains the inlet and outlet holes and the microchannels through which S-DMEM (Dulbecco's Modified Eagle's Medium (DMEM) supplemented with $10 \%(\mathrm{v} / \mathrm{v})$ foetal bovine serum (FBS, PAA, Germany)) flows, which nourishes and so maintains the viability of the artificial skin. The microchannels also incorporate a 20x20 mm section which encloses an array of $50 \mu \mathrm{m}$ diameter micropillars (see Fig. 2) which support a polycarbonate nanoporous membrane permitting the medium to diffuse through to the skin whilst also providing a platform to support the impedance sensor. The poly(dimethylsiloxane) (PDMS) layer is a compliant gasket which prevents leaks without stressing the silicon layers. The cover plate is there to house the skin and seal the fluidic system. The whole system is clamped together in an aluminium case which supports the system mechanically and facilitates connection to an external syringe pump, used to supply S-DMEM to the tissues.

The system can house and maintain the viability of a section of tissue $20 \times 20 \times 3 \mathrm{~mm}$ thick. As shown in Fig. 1, the top side of the tissue is exposed. In this way, accurate normal loads can be applied to the tissue by way of transient indentation by a rigid sphere, whilst the impedance of the tissue is simultaneously measured.

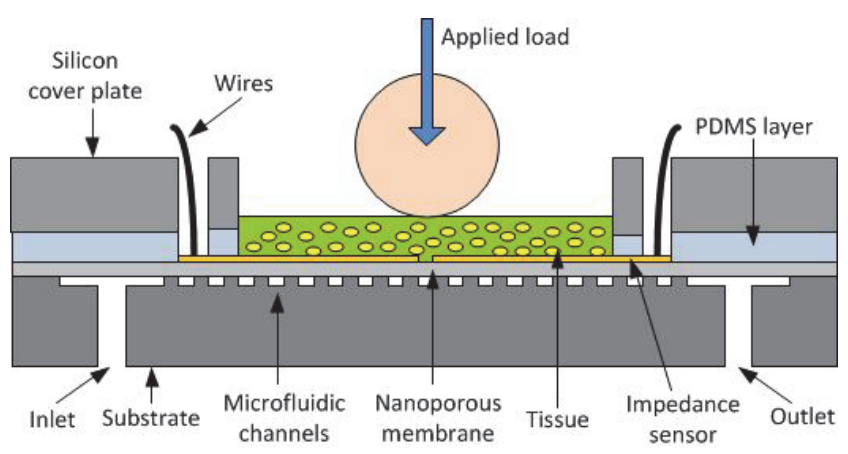

Fig. 1: Schematic of the microfluidic system with integrated bioimpedance sensor. Not to scale. 


\section{Fabrication of microfluidic system and bioimpedance sensor}

The microfluidic system and biosensor was fabricated in several components which were then assembled. The base consists of a $25 \times 60 \mathrm{~mm}$ chip fabricated from a single crystal silicon wafer $525 \mu \mathrm{m}$ thick (Si-Mat, Germany). Two etch processes were used. The first used photolithography consisting of SPR220-7 (Chestech, UK) spun onto the wafer to a thickness of $9 \mu \mathrm{m}$ and developed in MF-26A (Chestech, UK) to define the through holes that formed the inlet and outlet. The wafer was then etched through using deep reactive ion etching (DRIE). After cleaning, the process was then repeated, with the etch depth limited to $300 \mu \mathrm{m}$, to define the microfluidic channels and the micropillars (see Fig. 2).

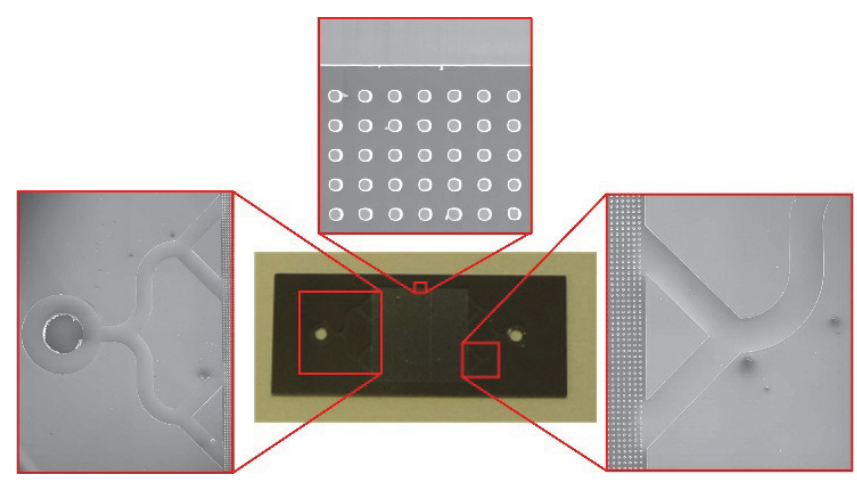

Fig. 2: Photo of patterned substrate showing microfluidic system. Insets: SEM images of sections of microfluidic system: (left) inlet; (center) micropillars; (right) microfluidic channels).

For the bioimpedance sensor, a shadow mask was fabricated using the same process described above to define the sensor geometry. The polycarbonate nanoporous membrane (Sterlitech, USA), which was $30 \mu \mathrm{m}$ thick and had $200 \mathrm{~nm}$ diameter pores, was secured to the back of the shadow mask and a $20 \mathrm{~nm}$ thickness layer of chromium and a subsequent $200 \mathrm{~nm}$ thickness layer of gold were thermally deposited onto the mask, resulting in selectively patterned electrodes on the membrane surface. The membrane was then removed from the mask and cut to size before being attached to the substrate using double sided $10 \mu \mathrm{m}$ thickness adhesive tape (Adhesives Research, USA). The geometry of the electrodes is shown in Fig. 3:

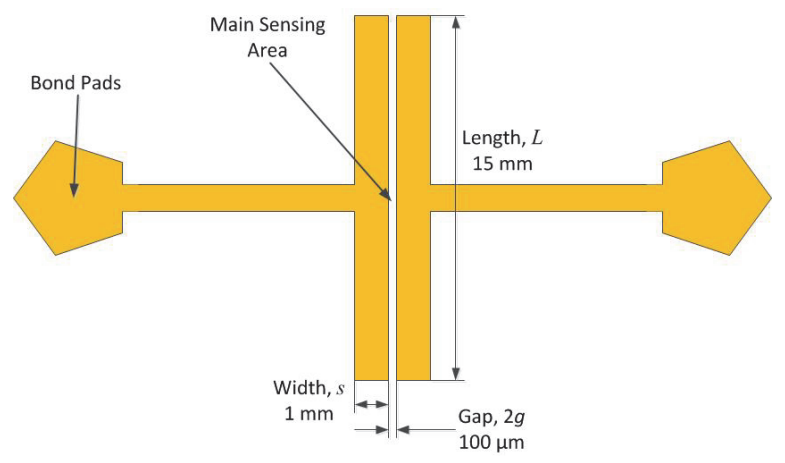

Fig. 3: Schematic and geometry of the impedance sensor.
The PDMS layer was formed by first creating a negative master mould from SU-8 2150 (Microchem, USA). The $500 \mu \mathrm{m}$ thick SU-8 mould was patterned using photolithography on a silicon wafer. The PDMS was formed from a two part mix (Sylgard 184, Dow Corning, USA) and poured into the mould and left to cure and outgas for 24 hours in ambient conditions $\left(20{ }^{\circ} \mathrm{C},<40 \% \mathrm{RH}\right)$. When cured, the PDMS layer was peeled away from the mould and trimmed to size.

The silicon cover plate was then fabricated by using the same photolithography and DRIE process as before to etch through a single crystal silicon wafer (Si-Mat, Germany) $525 \mu \mathrm{m}$ thick, thus defining a $20 \times 20 \mathrm{~mm}$ well which housed the tissue and holes permitting access to the bond pads on the bioimpedance sensor. The whole system was then assembled as shown in Fig. 1.

\section{Monitoring of the bioimpedance sensor}

The impedance of the bioimpedance sensor, and in turn the electrical properties of the surrounding material, are monitored by passing a steady AC signal with a frequency of $1 \mathrm{kHz}$ and amplitude $100 \mathrm{mV}$ through one electrode. The generated current is picked off from the other electrode by an inverting transimpedance amplifier, which acts as a virtual ground. The signal is then passed through a unitygain inverting amplifier to return the phase difference to the correct value. The output voltage is then given by:

$$
V_{\text {out }}=I R_{\text {gain }}
$$

$R_{\text {gain }}$ was measured to be $99.8 \Omega$. The input and output voltage were recorded using an external sound card (UCA202, Behringer, Germany). The sound card has two analogue voltage inputs which are measured at $44.1 \mathrm{kHz}$ at 24 bit resolution. It was interrogated using MatLab which was also used to convert the data to a .wav file for storage and to analyse the data using short time Fourier transform (STFT). To remove any errors in the phase difference measurements caused by the finite time it takes the sound card to move the data from the two analogue inputs into their respective data buffers, the same signal was passed from the function generator into the two inputs. The results show a $7.495^{\circ}$ phase difference, equivalent to a $20.8 \mu \mathrm{s}$ delay, between the two inputs and a difference in amplitude of a factor of 1.0091 .

Due to their length, the leads from the sensor and to the sound card had a significant impedance and acted as an impedance transformer. This affected the measurement of the load impedance which consisted of an effective resistance and reactance at the end of a transmission line. The amount of transformation was determined by the length of the leads and its characteristic impedance. The characteristic impedance, $Z_{0}$, was modelled as distributed 
elements (see Fig. 4) consisting of the series impedance, $Z$, of the line per metre:

$$
Z=R+i \omega L
$$

and shunt admittance, $Y$, of the line per metre:

$$
Y=G+i \omega C
$$

where $R, L, G$ and $C$ are the line's series resistance, inductance, shunt conductance and capacitance respectively. $\omega$ is the angular frequency and $i=\sqrt{-1}$.

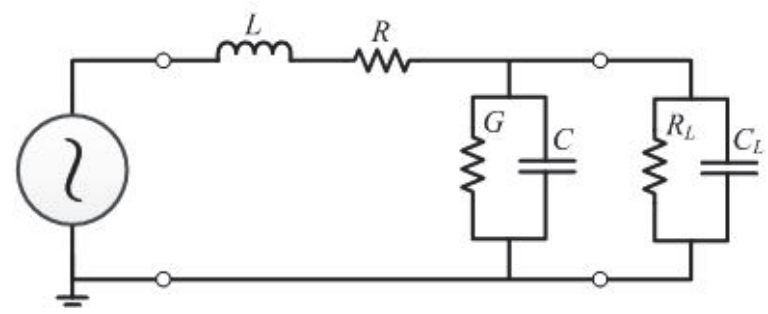

Fig. 4: The equivalent circuit for the impedance of the leads. $R_{L}$ and $C_{L}$ represent the load impedance, $Z_{L}$.

The characteristic impedance is the input impedance of an infinite line. The characteristic impedance of the leads of a given length was calculated by measuring the open circuit impedance, $Z_{o c}$, and the short circuit impedance, $Z_{s c}$, at a given frequency $(1 \mathrm{kHz})$ and using the relationship [33]:

$$
Z_{0}=\sqrt{Z_{o c} Z_{s c}}
$$

The input impedance of a lossy transmission line of length, $l$, is calculated using the transmission line equation [33]:

$$
Z_{\text {in }}=Z_{0} \frac{Z_{L}+Z_{0} \tanh (\gamma l)}{Z_{0}+Z_{L} \tanh (\gamma l)}
$$

$\gamma$ is the complex loss coefficient which can be given by:

$$
\gamma=\operatorname{atanh}\left(Z_{0} \frac{Z_{L}-Z_{\text {in }}}{Z_{\text {in }} Z_{L}-Z_{0}^{2}}\right) / l
$$

As stated before, the values that were actually measured by the soundcard is $V_{\text {in }}$ and $V_{\text {out }} . V_{\text {in }}$ is the input voltage as supplied by the function generator and is defined as the real part of:

$$
V_{i n}=|V| e^{i \omega t}
$$

where $|V|$ is the magnitude of the input voltage, $\omega$ is the angular frequency and $t$ is the time. $V_{\text {out }}$ is defined in eq. 1 . The current, calculated by rearranging eq. 1 , has the form:

$$
I=|I| e^{i(\omega t+\varphi)}
$$

$|I|$ is the amplitude of the current and $\varphi$ is the phase difference between $V_{i n}$ and $I$. The actual impedance measured is $Z_{\text {in }}$ which is defined as:

$$
Z_{\text {in }}=|Z| e^{i \theta}
$$

where the amplitude of the measured impedance is defined as:

$$
|Z|=\frac{|V|}{|I|}
$$

and the phase as:

$$
\theta=-\varphi
$$

Given the input impedance is now known and that $Z_{0}$ and $\gamma$ can be found from the calibration process discussed above, the load impedance, i.e. the impedance of the sensor can be shown to be (from eq. 5):

$$
Z_{L}=Z_{0} \frac{Z_{0} \tanh (\gamma l)-Z_{\text {in }}}{Z_{\text {in }} \tanh (\gamma l)-Z_{0}}
$$

Even though the actual equivalent circuit of the tissue is complex, what will be measured is the effective capacitance and resistance of the sensor, which were assumed to be lumped components in parallel as shown in Fig. 4. Splitting the load impedance into the real and imaginary components thus:

$$
Z_{L}=|Z| \cos \theta+i|Z| \sin \theta=R_{e q}+i X_{e q}
$$

allowed the load capacitance and resistance of the sensor to be calculated:

$$
\begin{gathered}
C_{L}=\frac{-X_{e q}}{\left(R_{e q}^{2}+X_{e q}^{2}\right) \omega}=\frac{-\sin \theta}{|Z| \omega} \\
R_{L}=\frac{R_{e q}^{2}+X_{e q}^{2}}{R_{e q}}=\frac{|Z|}{\cos \theta}
\end{gathered}
$$

These values can then be used to calculate the effective relative permittivity and resistivity of the tissue.

The conductivity sensor can be considered to be two coplanar electrodes in close proximity. If the electrodes are surrounded by a conductive medium, current can not only flow directly between the electrodes through the immediate gap, but also through the rest of the medium. As the length of the electrodes is much greater than the gap between them 
(see Fig. 3) the problem is essentially two dimensional in nature. However, the medium surrounding the sensors is not homogeneous. It is covered by a thin conductive layer of tissue exposed on top to the air and supported from underneath the sensors by a complex substrate (see Fig. 5).

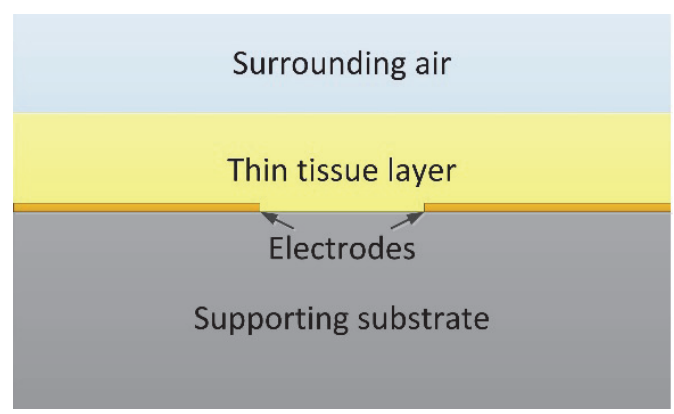

Fig. 5: The materials surrounding the conductivity sensor.

As the geometry is complicated, it is necessary to map the geometry of the different layers onto a parallel plate configuration where calculating the impedance is trivial. In this parallel plate configuration, each layer can be considered to act as a capacitor and resistor in parallel (see Fig. 6). For instance, the resistance, $R_{p}$, of a volume of conductive medium of resistivity $\rho$ between two identical parallel plates of cross-section $A$ and gap $d$ is given by:

$$
R_{p}=\frac{\rho d}{A}
$$

By defining:

$$
\begin{gathered}
k_{h s}=\frac{g}{s+g} \\
k_{h s}^{\prime}=\sqrt{1-k_{h s}^{2}}
\end{gathered}
$$

Where the suffix $h s$ denotes the mapping of the half-space, $g$ is the half the gap between the electrodes and $s$ is the width of the electrodes, the effective geometry can be found using a Schwartz-Christoffel transformation. The effective resistance due to the surrounding air is $[34,35]$ :

$$
R_{\text {air }}=\frac{\rho_{\text {air }}}{L} \frac{K\left(k_{h s}\right)}{K\left(k_{h s}^{\prime}\right)}
$$

where $K(k)$ is the complete elliptical integral of the first kind with argument $k$ and $L$ is the length of the electrodes. Similarly, if there are any conduction paths below the sensor, the effective resistance of the substrate, which includes the microfluidic system and support, can be given as:

$$
R_{s u b}=\frac{\rho_{s u b}}{L} \frac{K\left(k_{h s}\right)}{K\left(k_{h s}^{\prime}\right)}
$$

In a similar manner the geometry of the thin film of the conductive medium can be mapped onto the parallel plate geometry [36]. In this instance:

$$
k_{t f}=\frac{\tanh \left(\frac{\pi g}{2 h}\right)}{\tanh \left(\frac{\pi(s+g)}{2 h}\right)}
$$

and:

$$
k_{t f}^{\prime}=\sqrt{1-k_{t f}^{2}}
$$

where the suffix $t f$ denotes the thin film and $h$ is the thickness of that layer. The effective resistance of the tissue layer becomes:

$$
R_{\text {tissue }}=\frac{\rho_{\text {tissue }}}{L} \frac{K\left(k_{t f}\right)}{K\left(k_{t f}^{\prime}\right)}
$$

The resistance of the medium in the gap directly between the electrodes is simply given by:

$$
R_{g}=\frac{2 \rho_{\text {tissue }} g}{L t}
$$

where $t$ is the thickness of the electrodes. The capacitance of the electrodes can be found in a similar way. The capacitance of a parallel plate capacitor is known to be:

$$
C=\frac{\varepsilon_{0} \varepsilon_{r} A}{d}
$$

$\varepsilon_{0}$ is the permittivity of free space and $\varepsilon_{r}$ is the relative permittivity. Using the same conformal mapping as before, the capacitance of the air and substrate will be:

$$
\begin{gathered}
C_{\text {air }}=\varepsilon_{0} \varepsilon_{a i r} L \frac{K\left(k_{h s}^{\prime}\right)}{K\left(k_{h s}\right)} \\
C_{\text {sub }}=\varepsilon_{0} \varepsilon_{\text {sub }} L \frac{K\left(k_{h s}^{\prime}\right)}{K\left(k_{h s}\right)}
\end{gathered}
$$

Using eqs. 21 and 22, the capacitance of the thin tissue is: 


$$
C_{\text {tissue }}=\varepsilon_{0} \varepsilon_{\text {tissue }} L \frac{K\left(k_{t f}^{\prime}\right)}{K\left(k_{t f}\right)}
$$

The capacitance of the medium in the gap directly between the electrodes as given by:

$$
C_{g}=\frac{\varepsilon_{0} \varepsilon_{\text {tissue }} L t}{2 g}
$$

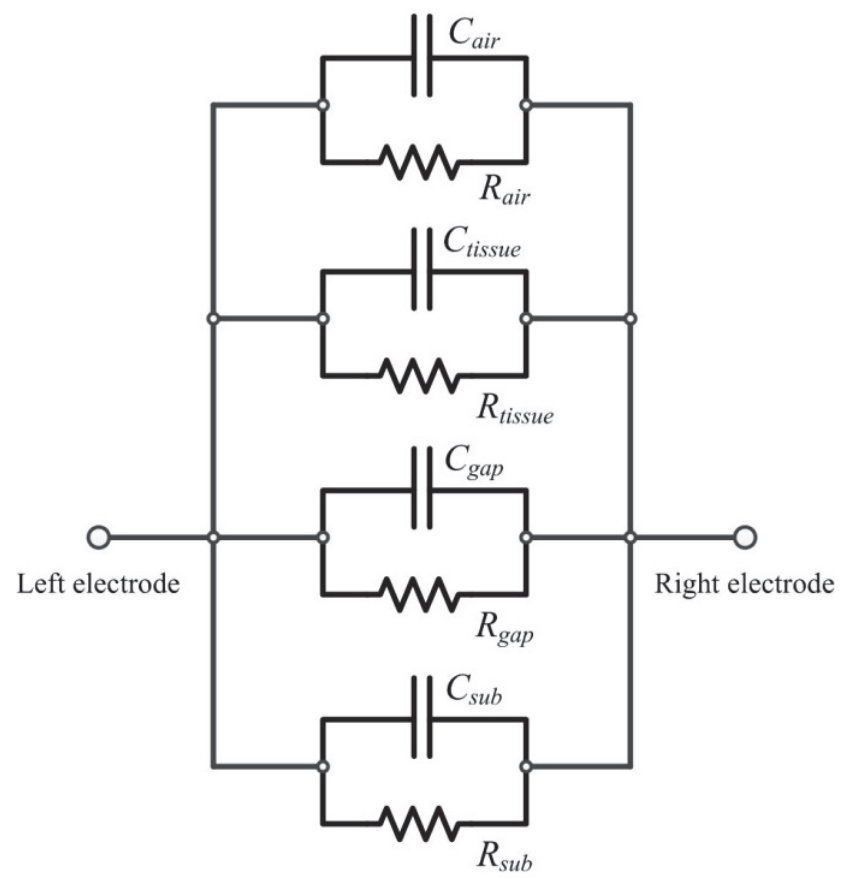

Fig. 6: Equivalent circuit of the multiple layers surrounding the sensor.

As shown in Fig. 6, the effective load resistance measured by the sensor can be seen to be the parallel combination of all the resistors and is given as:

$$
R_{L}^{-1}=R_{\text {air }}^{-1}+R_{\text {sub }}^{-1}+R_{\text {tissue }}^{-1}+R_{g}^{-1}
$$

Similarly, the effective load capacitance is the parallel combination or all the capacitors given as:

$$
C_{L}=C_{\text {air }}+C_{\text {sub }}+C_{\text {tissue }}+C_{g}
$$

The effective resistivity of the tissue can therefore be shown to be:

$$
\rho_{\text {tissue }}=L\left(\frac{K\left(k_{t f}^{\prime}\right)}{K\left(k_{t f}\right)}+\frac{\mathrm{t}}{2 \mathrm{~g}}\right)\left[\frac{1}{R_{L}}-\left(\frac{1}{R_{\text {air }}}+\frac{1}{R_{\text {sub }}}\right)\right]^{-1}
$$

The effective relative permittivity of the tissue can be shown to be:

$$
\varepsilon_{\text {tissue }}=\frac{C_{L}-\left(C_{\text {air }}+C_{\text {sub }}\right)}{\varepsilon_{0} L}\left[\frac{K\left(k_{t f}^{\prime}\right)}{K\left(k_{t f}\right)}+\frac{t}{2 g}\right]^{-1}
$$

\section{Extracellular matrix manufacture and cell encapsulation}

For the artificial skin, two different tissues were prepared, one consisting of a $50 \%$ volume of $5 \% \mathrm{w} / \mathrm{v}$ sodium alginate solution and $50 \%$ volume of S-DMEM, and the other of $50 \%$ volume of $5 \% \mathrm{w} / \mathrm{v}$ sodium alginate solution and $50 \%$ volume S-DMEM and cell suspension at a cell density of $10^{6}$ cells $/ \mathrm{mL}$.

$5 \% \mathrm{w} / \mathrm{v}$ sodium alginate solutions were prepared by mixing sodium alginate salt with distilled water at the appropriate amounts and at a temperature of $75^{\circ} \mathrm{C}$ for 2 hours. A $2 \mathrm{M} \mathrm{CaCl}_{2}$ solution was also prepared by mixing $\mathrm{CaCl}_{2}$ with distilled water. Both solutions were autoclaved for $15 \mathrm{~min}$ at a temperature of $120{ }^{\circ} \mathrm{C}$ in order to be sterilised for the cell encapsulation procedure. 3T3 fibroblasts were cultured for a week using the standard 3T3 protocol [37]. Cells were grown in S-DMEM and fed every $2^{\text {nd }}$ day of the cell culture. The fibroblasts were trypsinised on day 7 of the cell culture in order to be encapsulated in the alginate hydrogels. For the cell encapsulation procedure, a cell density of $10^{6}$ cells $/ \mathrm{mL}$ was used. SDMEM, with and without cells, was added to the alginate solution immediately prior to being added to the mould.

In a comparable manner to the procedure used in [38], the two solutions were pipetted in poly(styrene) dishes of diameter $136 \mathrm{~mm}$ and $17 \mathrm{~mm}$ depth and between two cellulose filter papers soaked in $2 \mathrm{M} \mathrm{CaCl}_{2}$ solution. In the poly(styrene) dishes, steel discs of diameter $21.5 \mathrm{~mm}$ and thickness $3 \mathrm{~mm}$ were placed to achieve gel discs of homogeneous gel thickness. Above the upper filter paper another poly(styrene) dish was placed in order to achieve gel discs of uniform flatness. All samples were left to gelate for $1 \mathrm{hr}$. Afterwards square pieces of dimensions $\sim 1.0 \times 1.5$ $\mathrm{cm}$ of each gel were cut and placed on the device and were measured as described previously.

In order to examine the cellular viability post encapsulation, sections of $1 \mathrm{~mm}$ thickness were taken from the centre of alginate discs containing $3 \mathrm{~T} 3$ cells using a sterilized blade. The sections were immersed in $0.2 \mu \mathrm{L}$ calceinacetoxymethylester (calcein-AM) for $15 \mathrm{~min}$ and 2.5 $\mu \mathrm{L}$ propidiumiodide (PI) for $5 \mathrm{~min}$ in S-DMEM at $37{ }^{\circ} \mathrm{C}$. The calcein-AM was cleaved to form calcein in the presence of esterases in live cells resulting in photon emission at a wavelength around $515 \mathrm{~nm}$. In the case of dead-cells, the PI penetrated the cell and nuclear membrane and intercalated the DNA resulting in a photon emission at a wavelength around $650 \mathrm{~nm}$. All samples were visualized using fluorescence microscopy. 


\section{Indentation}

Indentation experiments took the form of stress relaxation measurements. These were performed at $18{ }^{\circ} \mathrm{C}$ and $40 \%$ relative humidity using a Z030 mechanical tester (Zwick/Roell, UK). In all the experiments, an insulating and hydrophobic $9 \mathrm{~mm}$ diameter poly(propylene) sphere was brought into contact with the tissue using a $5 \mathrm{mN}$ compressive preload before being indented into the material at a rate of $0.01 \mathrm{~mm} / \mathrm{s}$ to a specific depth and then held at that depth for up to 300 seconds, whilst monitoring the force. Two main sets of experiments were conducted defined as small strain and large strain experiments. For the small strain experiments the sample was indented to depths of $20,40,60,80$ and $100 \mu \mathrm{m}$ in succession. This equates to maximum strains of c.a. $0.94,1.33,1.63,1.89$, and $2.11 \%$. For the large strain experiments the indentation depths were $250,500,750$ and $1000 \mu \mathrm{m}$ or to strains of 3.33, 4.71, 5.77 and $6.67 \%$, assuming Tabors' empirical effective indentation strain [39]. Force and indentation depth were measured at a rate of 100 samples per second.

\section{Results}

\section{Calibration}

To calculate the characteristic impedance of the circuit, the bioimpedance sensor was detached and the measurement conducted with the connectors connected together (shorted configuration) and left separated (open configuration). The measured impedances are shown in Table 1. The characteristic impedance was calculated using eq. 4.

\begin{tabular}{c|c|c|c} 
& $\begin{array}{c}\text { Shorted } \\
\text { Impedance }\end{array}$ & $\begin{array}{c}\text { Open } \\
\text { Impedance }\end{array}$ & $\begin{array}{c}\text { Characteristic } \\
\text { Impedance }\end{array}$ \\
\hline $\begin{array}{c}\text { Magnitude } \\
(\Omega)\end{array}$ & $153.03 \pm 0.01$ & $4564.6 \pm 0.1$ & $835.76 \pm 0.02$ \\
$\begin{array}{c}\text { Phase } \\
(\text { degs })\end{array}$ & $-184.1 \pm 0.1$ & $5.5 \pm 0.1$ & $-89.3 \pm 0.1$
\end{tabular}

Table 1: Values from characteristic impedance measurement. Errors to one standard deviation.

To calculate the complex loss coefficient (see eq. 6) a 15 $\mathrm{k} \Omega$ resistor was placed in the connectors to give the circuit a known load impedance, $Z_{L}$. The resulting input impedance, $Z_{\text {in }}$, was measured for a period of $30 \mathrm{~s}$, five times and was calculated, using Fourier transforms over the entire sample, to have an average magnitude of $22851.67 \pm 0.01 \Omega$ and phase of $-2.6^{\circ} \pm 0.1^{\circ}$. Using the values given in Table 1 for the characteristic impedance, $Z_{0}$, the complex loss coefficient was calculated to be $\gamma=$ $0.0014+i 0.019$. The length of the line, $l$, was measured to be $1 \mathrm{~m}$.
To measure the impedance of the sensor without the tissue and only due to the influence of the substrate and surrounding air, the sensor was connected to the circuit and placed on the equipment as it would be placed during an indentation experiment. The impedance was measured as $Z_{\text {air,sub }}=20158.04-i 1736.48 \Omega$. As the air and substrate are treated as leaky capacitors in parallel, see Fig. 6 , the effective resistance and capacitance of the system without the tissue is, respectively:

$$
\begin{gathered}
\left(\frac{1}{R_{\text {air }}}+\frac{1}{R_{\text {sub }}}\right)^{-1}=20307.63 \pm 0.01 \Omega \\
C_{\text {air }}+C_{\text {sub }}=4.49 \pm 0.005 \mathrm{nF}
\end{gathered}
$$

\section{Live-dead staining of fibroblasts encapsulated in alginate hydrogels}

All fibroblast encapsulated alginate hydrogels were stained using PI and AM as described previously. Fig. 7 shows the images of $50 \%$ alginate and 50\% S-DMEM with a cell density of $10^{6}$ cells $/ \mathrm{mL}$ of S-DMEM after testing. As can be observed, the majority of the cells are viable, and so were 'alive' during testing.

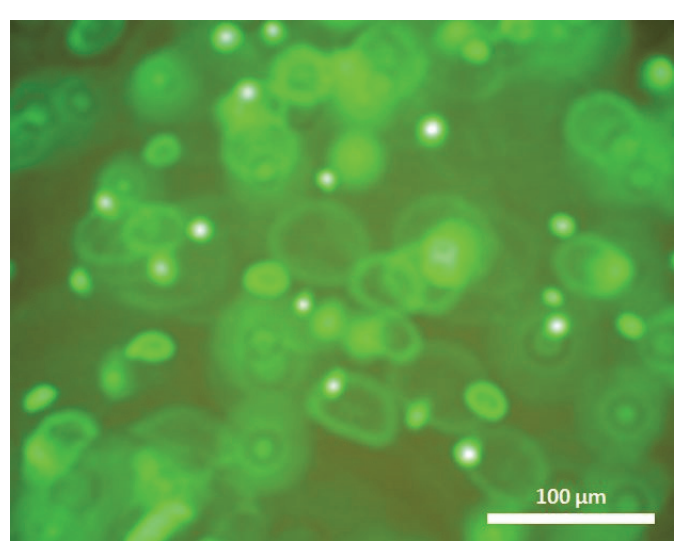

Fig. 7: Fluorescence microscopy images of cells stained with a live-dead assay encapsulated into the alginate hydrogels.

\section{Indentation experiments on acellular alginate}

Fig. 8 shows the force measured during sequential small strain indentation of acellular hydrogel consisting of $50 \%$ volume of $5 \% \mathrm{w} / \mathrm{v}$ sodium alginate solution and $50 \%$ volume of S-DMEM. In each experiment, the sphere was bought into contact with the hydrogel with a preload of 5 $\mathrm{mN}$ before the indentation depth was increased at a constant rate of $10 \mu \mathrm{m} / \mathrm{s}$ to depths of $20,40,60,80$ and $100 \mu \mathrm{m}$ in succession and then held at those depths for up to five minutes. 


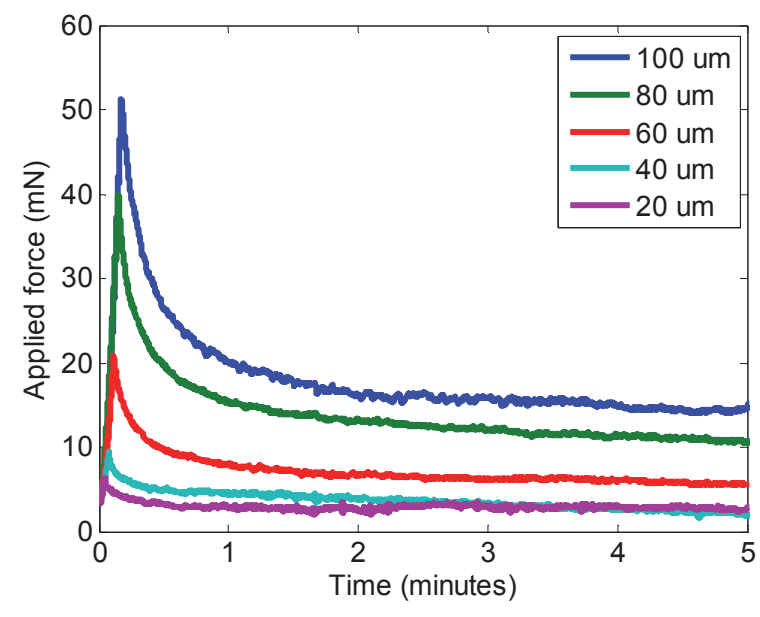

Fig. 8: Measured force during small strain indentation experiments on acellular alginate. Legend denotes final indentation depth.

The impedance of the bioimpedance sensor was monitored continuously during each indentation experiment. The effective resistivity and permittivity of the alginate/SDMEM hydrogel was calculated using eqs. 32 and 33. The results are shown in Figs. 9 and 10. In both figures, a slight decrease in the resistivity and permittivity in each data set is seen for a duration comparable to the ramp time of the indentation. During the 'hold phase' where the strain is kept constant, the resistivity is seen to creep and continue to rise for the duration of the experiment. This relaxation is most significant at an indentation depth of $20 \mu \mathrm{m}$ although it can be observed for all experiments. Contrary to the trends seen in the resistivity, after the initial decrease, the relative permittivity is seen to continue to reduce during the hold phase. During the hold phase, the trends seen in both the resistivity and the permittivity of the alginate/S-DMEM hydrogel are generally smooth and a clear function of the applied strain.

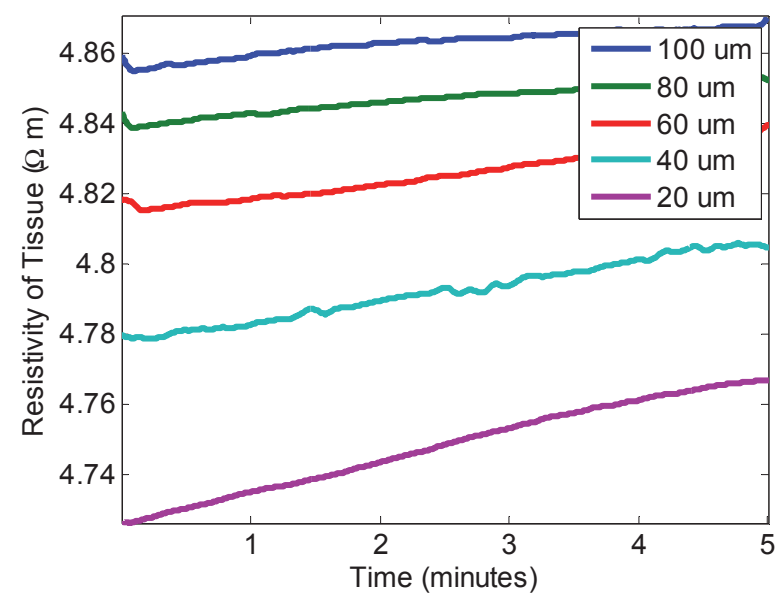

Fig. 9: Measured resistivity of acellular alginate during small strain indentation experiments calculated from eq. 32. Legend denotes final indentation depth.

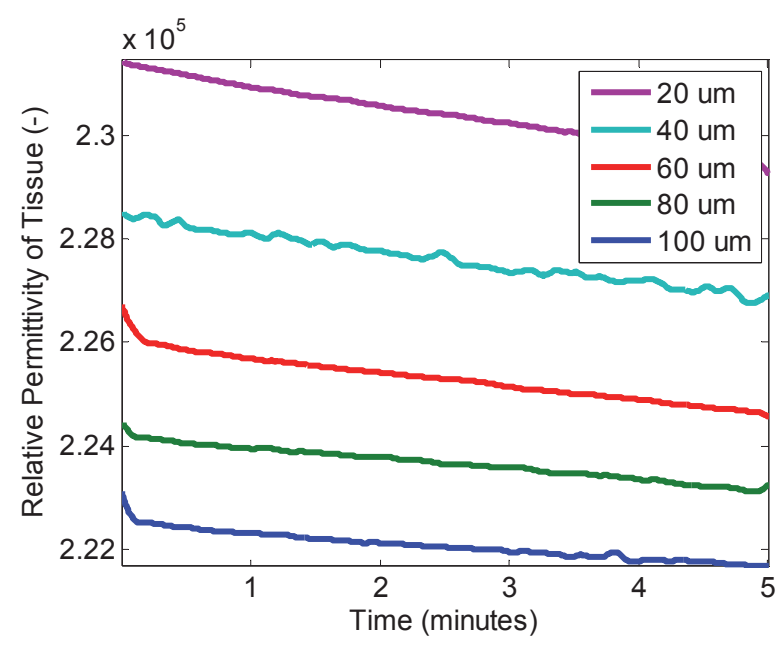

Fig. 10: Measured relative permittivity of acellular alginate during small strain indentation experiments calculated from eq. 33 . Legend denotes final indentation depth.

In Fig. 11, the force measured during the large strain indentation tests are shown. As compared to the data shown in Fig. 8, the response appears to be non-linear, suggesting some additional strain-dependent phenomena relating to the hydrogel polymer network that will be discussed in the subsequent section. These phenomena also affects the impedance of the alginate/S-DMEM hydrogel. In Fig. 12, where the resistivity of the alginate/S-DMEM hydrogel during indentation is shown, the initial decrease is again observed in the same manner as in Fig. 9 whilst the strain is still small, but as the strain is increased and becomes large, the resistivity starts increasing again, before creeping during the hold phase in the indentation experiment. In Fig. 12, the difference between the ramp phase and the hold phase in the indentation experiment is clearly discerned.

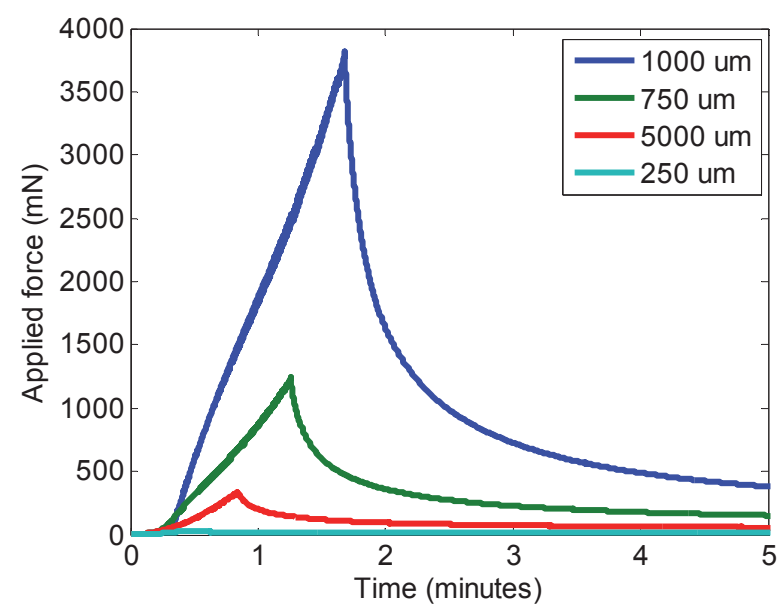

Fig. 11: Measured force during large strain indentation experiments on acellular alginate. Legend denotes final indentation depth. 


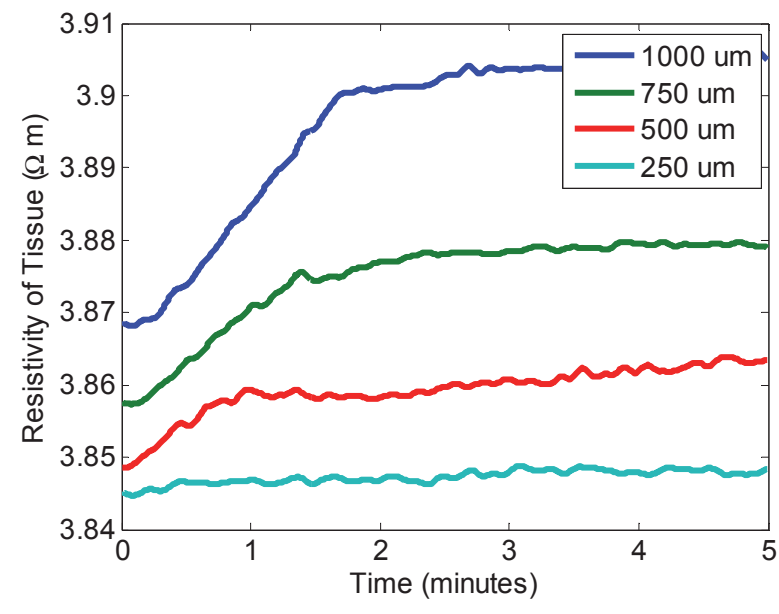

Fig. 12: Measured resistivity of acellular alginate during large strain indentation experiments calculated from eq. 32. Legend denotes final indentation depth.

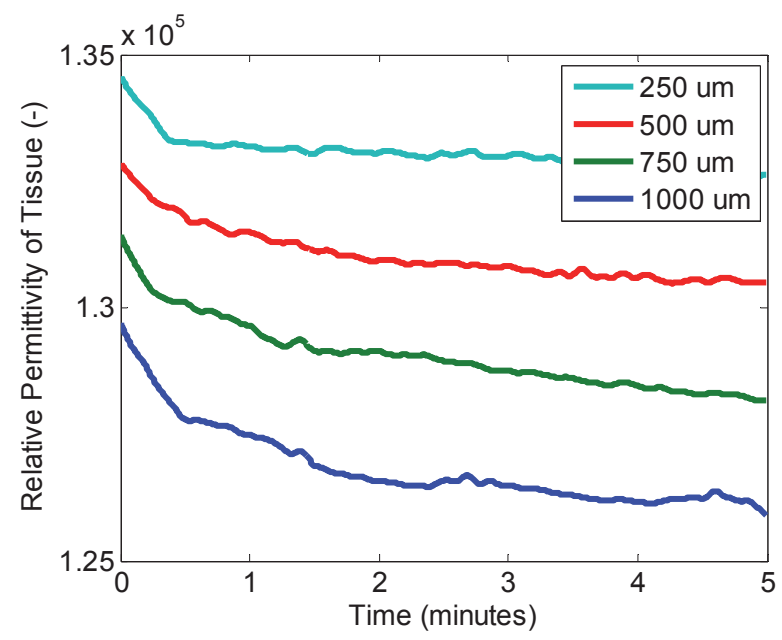

Fig. 13: Measured relative permittivity of acellular alginate during large strain indentation experiments calculated from eq. 33. Legend denotes final indentation depth.

In Fig. 13, the trends are comparable to those seen in Fig. 10 , in that there is a fairly linear decrease in relative permittivity of the alginate/S-DMEM hydrogel as the strain increases, until the strain becomes large and the response becomes more non-linear. During the hold phase, the relative permittivity continues to relax, as also seen in the small strain experiments, with the difference that for large strains, the extent of the relaxation seems to increase with peak strain.

Indentation experiments on artificial skin comprised of fibroblasts encapsulated in alginate

The full range of experiments conducted in the previous samples using acellular samples were repeated with samples comprised of alginate/S-DMEM hydrogel encapsulated fibroblasts. Comparing the small strain indentation data (Figs. 8 and 14) suggests that the rheology for the two tissue types is comparable with no obvious phenomenon due to cellular activity.

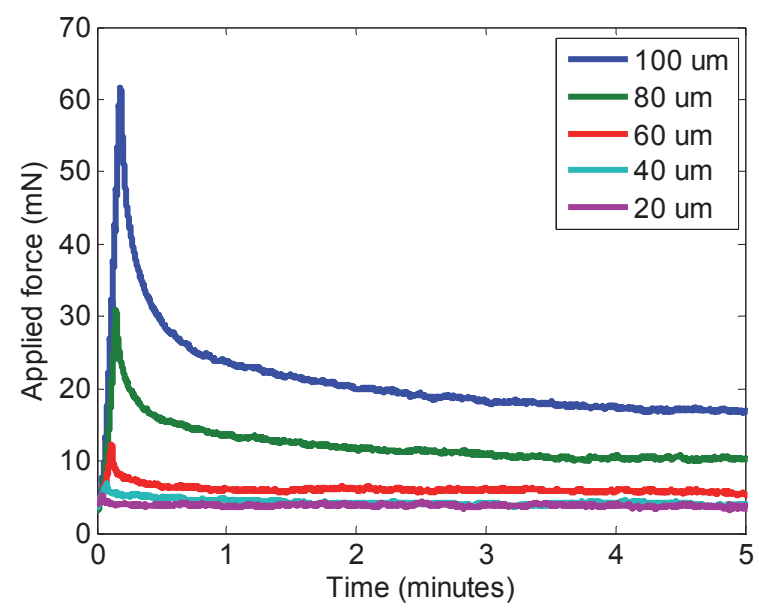

Fig. 14: Measured force during small strain indentation experiments on alginate hydrogel encapsulated fibroblasts. Legend denotes final indentation depth.

However, in the impedance data, i.e. the measured effective resistivity and relative permittivity for the cellular sample (see Figs. 15 and 16), there are some clear differences between the acellular (Figs. 9 and 10) and cellular samples. Notably in the resistivity data (Fig. 15) the response for the $20 \mu \mathrm{m}$ indentation is markedly different from its corresponding acellular experiment (Fig. 9). One might suggest that the response to the $20 \mu \mathrm{m}$ indentation is an artefact, perhaps due to poor contact due to surface roughness or nanofilm production due to syneresis. However, the force data in Fig. 14 does not suggest this. The experiments were repeated several times with three data sets presented in the Supporting Information (see Fig. S1). As can be seen, the anomalous response to the $20 \mu \mathrm{m}$ indentation is present in each data set involving viable cells, but not during the acellular experiments. The exact reason for this is currently under investigation, but possible causes are discussed below. Also at higher strains, there is other evidence of cellular activity not observed in the force data, in the form of well-defined half-cycle oscillations leading to a reduction in resistivity beyond that caused by any external mechanical event. Again as seen in Fig. S1 in the Supporting Information, the tissue resistivity and relative permittivity show a similar dependence on indentation depth for each run. The oscillations seen in Fig. 15 can also be observed in the other runs (see Fig. S1). Interestingly, the oscillations seem to occur sooner for higher strains, albeit at a comparable amplitude, i.e. at 30-45 s for $100 \mu \mathrm{m}$ indentations, $110-150 \mathrm{~s}$ for $80 \mu \mathrm{m}$ indentations, 240-280 s for $60 \mu \mathrm{m}$ indentations. For 20 and $40 \mu \mathrm{m}$ indentations, the response is not so simple. It should be noted that the initial magnitude of the tissue resistivity and relative permittivity differs between runs. Taking the tissue resistivity response to the $100 \mu \mathrm{m}$ indentation as an example, the mean initial tissue resistivity is $4.265 \Omega \mathrm{m}$, with a standard deviation of 
$0.36 \Omega \mathrm{m}$. This equates to a $\pm 8 \%$ deviation. This compares well with the experimental indentation data for similar tissues in [38] where the Young's moduli have standard deviation in the range $\pm 4-10 \%$, suggesting that this deviation is typical for biological tissues.

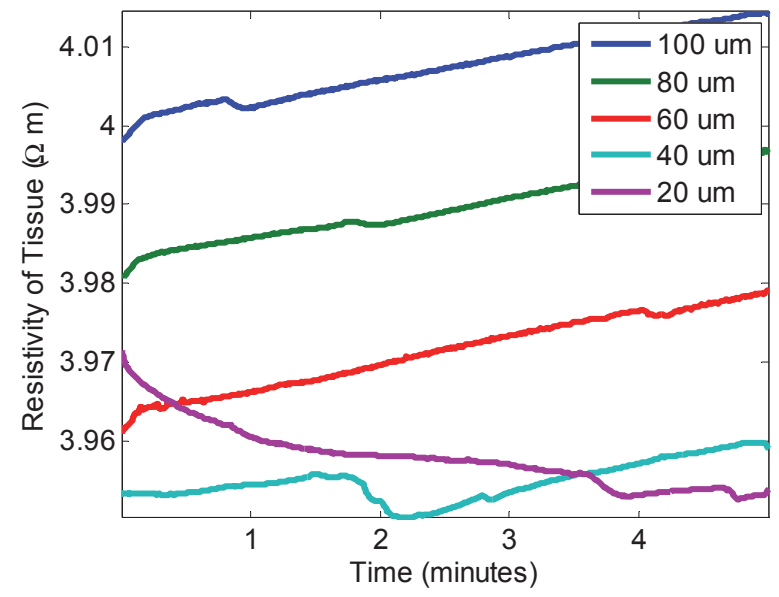

Fig. 15: Measured resistivity of alginate hydrogel encapsulated fibroblasts during small strain indentation experiments calculated from eq. 32. Legend denotes final indentation depth.

Deviations in the permittivity, corresponding to the phenomena in the resistivity, were also observed (Fig. 16) over a generally extended time scale to that observed in Fig. 15.

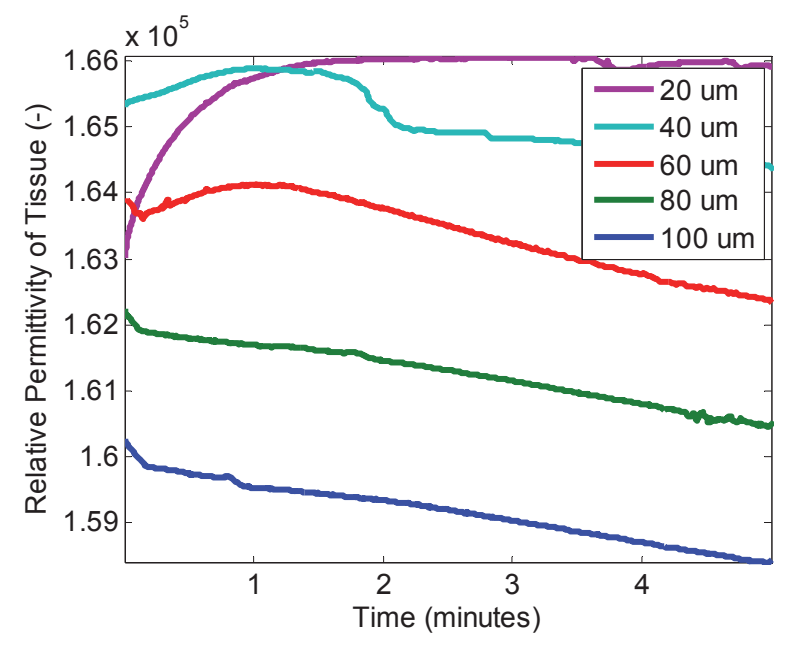

Fig. 16: Measured relative permittivity of alginate hydrogel encapsulated fibroblasts during small strain indentation experiments calculated from eq. 33. Legend denotes final indentation depth.

The large strain force data (see Fig. 17) is also comparable to the equivalent acellular experiments (Fig. 11) as it was for the small strain experiments. However, except for a significant change in the relative permittivity for the case where the indentation depth is $250 \mu \mathrm{m}$, little deviation in the resistivity and relative permittivity (Figs. 18 and 19 respectively) is observed between the acellular and cellular samples. Possible reasons for the observed phenomena are discussed in the next section.

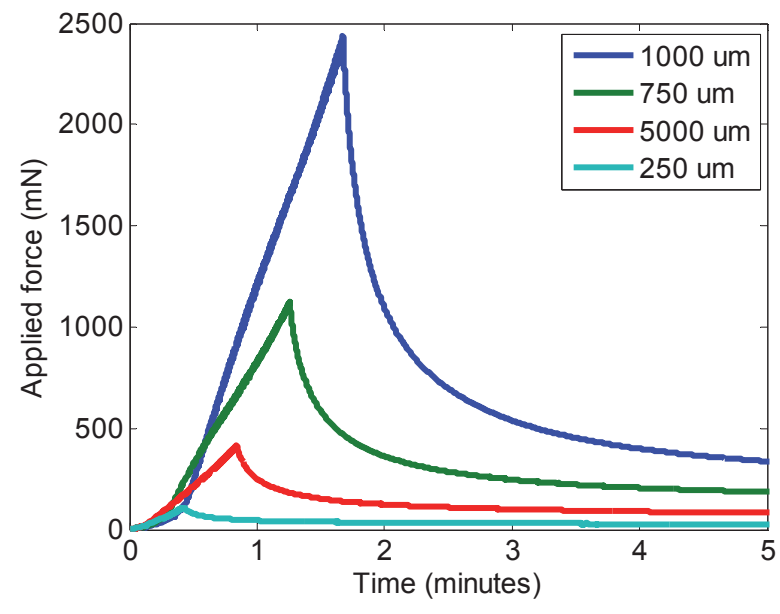

Fig. 17: Measured force during large strain indentation experiments into alginate hydrogel encapsulated fibroblasts. Legend denotes final indentation depth.

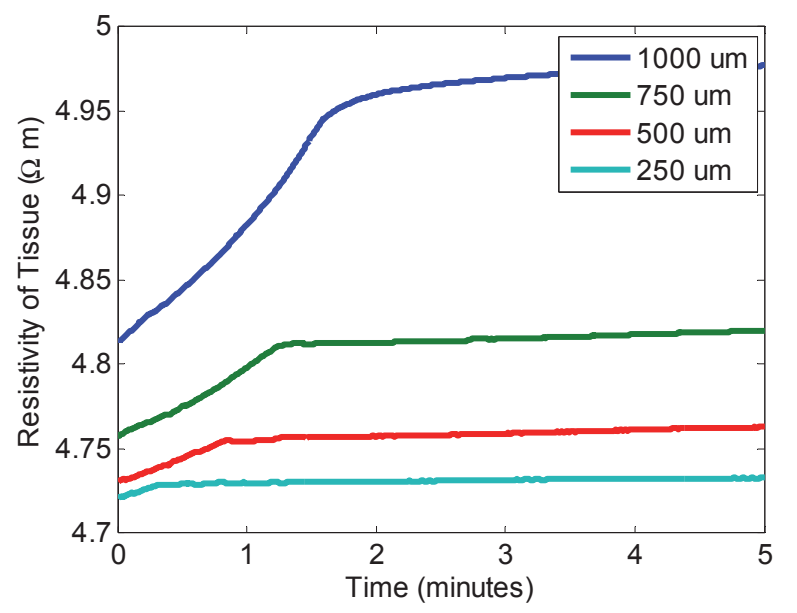

Fig. 18: Measured resistivity of alginate hydrogel encapsulated fibroblasts during large strain indentation experiments calculated from eq. 32. Legend denotes final indentation depth.

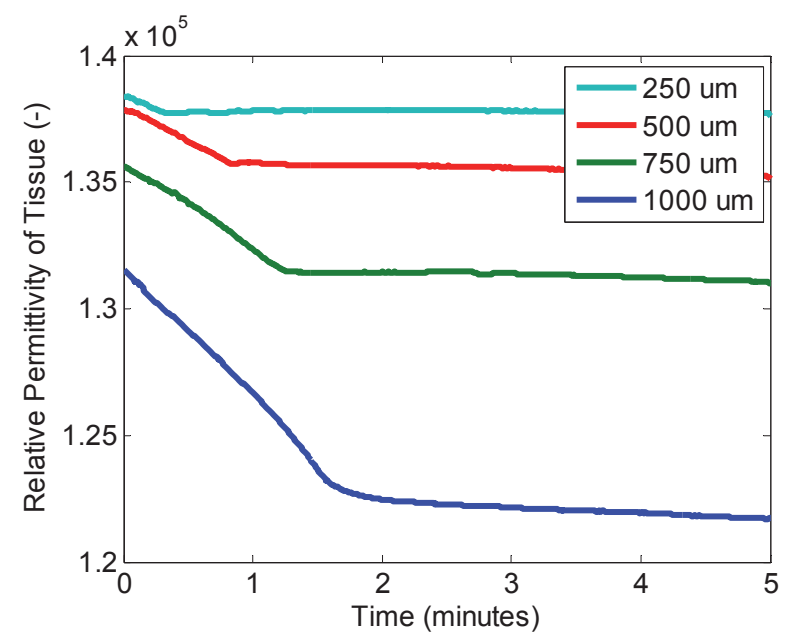

Fig. 19: Measured relative permittivity of alginate hydrogel encapsulated fibroblasts during large strain indentation experiments calculated from eq. 33. Legend denotes final indentation depth. 


\section{Discussion}

\section{Rheology of tissue}

After correcting for the finite thickness of the tissue and the finite ramp time in the same manner as described in [40], it was observed that the transient small strain viscoelastic properties of both the acellular and cellular tissues, as measured in Figs. 8 and 14, are well described by a relaxation function, $\Psi(\tau)$, of the form [40]:

$$
\Psi(\tau)=2 G_{\infty}+2\left(G_{1} e^{-\tau / T_{1}}+G_{2} e^{-\tau / T_{2}}\right)
$$

Here $G_{\infty}$ is the steady state shear modulus, or the shear modulus of the tissue when the strain has been held constant for sufficient time that the stress is constant. $\tau$ is the experiment time, $T_{n}$ are the characteristic relaxation time constants and $G_{n}$ are coefficients of the Prony series and are generally without formal physical definitions in this phenomenological model. A standard non-linear least squares algorithm which utilises a trust region approach [41] was used to fit the data in Figs. 8 and 14 to the viscoelastic thin film indentation force presented in [40]. The properties for each tissue were calculated to be the same regardless of indentation depth for the small strain indentation experiments, up to a coefficient of determination of at least 0.98 . The quality of the fits are shown in the Supporting Information (see Fig. S2 and Table $\mathrm{S} 1)$. The coefficients for the relaxation modulus are shown in Table 2:

\begin{tabular}{c|c|c} 
& Acellular Tissue & Cellular Tissue \\
\hline$G_{\infty}(\mathrm{kPa})$ & $15.83 \pm 0.9$ & $16.61 \pm 1.4$ \\
$G_{0}(\mathrm{kPa})$ & $69.91 \pm 6.6$ & $82.29 \pm 18.5$ \\
$G_{1}(\mathrm{kPa})$ & $36.05 \pm 5.2$ & $51.98 \pm 14.6$ \\
$G_{2}(\mathrm{kPa})$ & $15.03 \pm 1.1$ & $13.69 \pm 2.5$ \\
$T_{1}(\mathrm{~s})$ & $7.61 \pm 0.9$ & $5.22 \pm 1.0$ \\
$T_{2}(\mathrm{~s})$ & $60.27 \pm 11.9$ & $75.35 \pm 2.2$
\end{tabular}

Table 2: The mean coefficients for the relaxation modulus and time constants as calculated by fitting to the small strain indentation data given in figures 8 and 14. Errors given to one standard deviation.

As shown in Table 2 and demonstrated in Figs. 8 and 14, the alginate/S-DMEM hydrogel with encapsulated fibroblasts has an instantaneous shear modulus, $G_{0}$, i.e. the shear modulus of the tissue experienced by a suddenly applied load, 15\% higher than the acellular tissue. This is likely to be due to error in the assumed tissue thickness, given the cell concentration of $10^{6}$ cells $/ \mathrm{mL}$ per $50 \%$ volume of hydrogel and the average spherical diameter of fibroblasts is $18 \mu \mathrm{m}$ [42], as this suggests a volume fraction of cells in the cellular tissue of $0.15 \%$ which should not affect the mechanical properties of the tissue significantly, even if the cells have a large modulus [43].

One way the fibroblast population could significantly affect the mechanical properties of the alginate/S-DMEM hydrogel is through adhesion. In the very simplest of terms, fibroblasts 'normally' interact with the extracellular matrix by way of focal adhesions and other adhesion structures [44]. Focal adhesions are integrin-based and form strong links between the extracellular polymer matrix and the cells cytoskeleton. Another adhesion structure, fibrillar adhesion $[44,45]$, connects the cell to the extracellular matrix via fibrils of fibronectin. However, the extracellular matrix used here is a hydrogel formed from alginate which is a block copolymer composed of regions of (1-4)-linked $\beta$-Dmannuronic acid ( $\mathrm{M}$ units), regions of $\alpha$-L-guluronic acid ( $\mathrm{G}$ units) and atactically arranged $\mathrm{M}$ and $\mathrm{G}$ units. In an aqueous environment, the carboxylic acid groups in the $G$ units dissociate and become charged. This allows divalent cations like $\mathrm{Ca}^{2+}$ to form ionic crosslinks between $\mathrm{G}$ units of adjacent alginate chains which results the gelation of the alginate solution [46]. Not all dissociated carboxyl groups will have an associated $\mathrm{Ca}^{2+}$ ion and so the alginate will be, in general, hydrophilic. This inhibits protein adsorption and precludes cell adhesion [47]. So while relatively little is known about cell-matrix adhesive structures in 3D matrices [48], it is apparent that the fibroblasts are unlikely to attach to the alginate/S-DMEM hydrogel. This is confirmed in the spherical shape of the fibroblasts within the alginate/SDMEM hydrogel as seen in Fig. 7 and in other published alginate structures [49]. The comparable steady state shear moduli, $G_{\infty}$, for the two tissues confirms that the cells are not firmly attached to the alginate/S-DMEM hydrogel. If they were, the adhesions would add extra structural support to the polymer network and make it stiffer.

The force data from the large strain indentation experiments, as shown in Figs. 11 and 17, does not fit well to the linear viscoelastic theory presented in [40]. This is expected, as the geometry of the indentation deviates from the quadratic approximation used and the small strain assumption is no longer suitable. Moreover, the forcedisplacement relationship shown in Figs. 11 and 17 is indicative of strain-hardening effects in the alginate [50]. This is because the ionic crosslinks in alginates, as described above, are generally most stable when between long blocks of $G$ units which form stiff junction zones connected by network chains. This is often referred to as the "egg-box model" [51]. These junction zones are significantly large, sometimes larger than the chain segments between crosslinks [52]. They are also considerably more rigid and exhibit a restoring force that increases with strain. These junction zones are not easily deformed at small strains and so only the network chains would be stretched in this situation. Therefore, at small strains the alginate shows a linear stress-strain relationship 
[50] that can be predicted by a Gaussian network chain theory [53] and the linear viscoelastic theory used. However, at larger strains, the Gaussian model needs to be combined with Doi and Kuzuu's model of nonlinear elasticity of rodlike macromolecules in a condensed state $[50,54]$ in order to have a theory that accurately predicts the mechanical behaviour of the alginate/S-DMEM hydrogel in a viscoelastic paradigm.

The fit to the data in Table 2 assumes that the hydrogel is a linearly viscoelastic material. This is frequently assumed $[55,56]$ as a linear viscoelastic model permits the simplest calculation of the transient shear moduli properties of the material by applying the Boltzmann superposition principle to the known solution of the indentation of elastic materials problem $[57,58]$. However, this model does not truly represent the physics of the alginate/S-DMEM hydrogel. The polymer matrix only takes up $2.5 \%$ of the mass of the alginate/S-DMEM hydrogel, the rest is comprised of water, salts which are likely to be dissociated, larger molecules such as proteins and carbohydrates from the S-DMEM and sol formed from uncrosslinked alginate, and in the cellular case, fibroblasts. A number of models have been proposed by various research teams to describe similar materials, such biological tissues and swollen polymer networks [59-65]. Some of these models have been shown to be equivalent [57, 66, 67], however, there is a debate as to how 'correct' these models are. Naturally, some models are only accurate for specific materials, but there is evidence to suggest some objections are a significant cause for concern $[62,63,68]$. A further issue with these models is that they are generally mathematically involved and often numerical methods are needed to fit to experimental data. This is particularly true of indentation experiments where the stress, strain and ion concentration fields are inhomogeneous due to complex boundary conditions and difficult to solve for.

That said, there are enough commonalities to qualitatively describe the physical phenomenon that has been observed in the force and impedance data. As the sphere is pushed in to the alginate/S-DMEM hydrogel surface, the polymer network is deformed under the compressive stress. At short time limits, due to the low permeability of the hydrogel [69] the solvent hasn't had time to migrate away from the area of high stress resulting in high hydraulic pressure [70] and increased chemical potential of the solvent [71]. These fluid forces cause the polymer network to expand in the radial direction in a manner that the material appears to behave as a nearly incompressible material. This effect may be compounded by the fixed charges along the alginate polymer chains due to the dissociation of the carboxyl groups. The excess of ions may create an additional pressure known as Donnan osmotic pressure which increases the apparent hydraulic pressure [72]. However, the additional salt introduced via the S-DMEM may result in a hypertonic solution which could negate this effect [70]. As time progresses, the fluid flows slowly through the network and the polymer gradually recoils in the radial direction, the fluid pressure decreases and the dilation becomes more negative [70]. This continues during the 'hold' phase of the indentation when the indentation depth of the sphere is kept constant until a steady state is reached and the chemical potential of the solvent and solutes tend to zero. This can be observed in Fig. 8, where the measured force increases quickly with indentation depth with corresponding increase in the compressive stress in the polymer network and hydraulic pressure, and then relaxes when the indentation depth is held constant and the fluid has time to flow away and the polymer network can recoil.

\section{Conductivity of tissue}

The phenomena described in the previous section also correlates with the measured resistivity. If we assume the salts included in the S-DMEM (see Table 3) are fully dissociated and constitute the bulk of the charge carriers, we can calculate the conductivity, $\sigma$, of the hydrogel under no flow conditions, assuming no influence of the polymer network, using the following expression [73]:

$$
\sigma=\frac{F^{2} \phi^{w}}{R T} \sum_{i=1}^{n} z_{i}^{2} c_{i} D_{i}
$$

where $F$ is the Faraday constant, $\phi^{w}$ is the water volume fraction, $R$ is the gas constant, $T$ is the absolute temperature, and $z, c$ and $D$ are the valence, concentration and diffusivity of each ion respectively. The summation is over all ions. Using the values in Table 3 and assuming a water volume fraction of 0.97 , the nominal resistivity was calculated to be $1.32 \Omega \mathrm{m}$, which is comparable, but less than the resistivity measured in Fig. 9. Naturally, the mobility of the solute is diminished by the greater viscosity of the S-DMEM compared to pure water. As well as this, many models have been put forward to explain the effect the polymer network has on the diffusivity of the solute (see [74] for a review of most models). Recently, an empirical model [75] has been proposed that relates the diffusivity of the solute to the permeability of the polymer network, $\kappa$, and to the Stokes' radius of the solute, $r_{s}^{i}$, which could explain the discrepancy:

$$
D_{i}=D_{i}^{0} \exp \left[-\alpha\left(\frac{r_{s}^{i}}{\sqrt{\kappa}}\right)^{\beta}\right]
$$

where $D_{i}^{0}$ is the diffusivity of the solute in aqueous solutions, i.e. those given in Table $3, \alpha$ and $\beta$ are two positive parameters that depend on the structure of the polymer network. Furthermore, it has been suggested that 
the permeability of the polymer network is a function of the dilation, $e[76]$ :

$$
\kappa=\kappa_{0}\left(\frac{\phi_{0}^{w}+e}{\phi_{0}^{w}}\right)^{n}
$$

where $\kappa_{0}$ and $\phi_{0}^{w}$ are the permeability of the polymer network and water volume fraction of the hydrogel at reference, i.e. prior to indentation when $e=0$, and $n$ is an empirical factor. This factor, when combined with the change in water volume fraction with dilation [77]:

$$
\phi^{w}=\frac{\phi_{0}^{w}+e}{1+e}
$$

expresses how the conductivity calculated by eq. 37 is a function of strain and time and can exhibit the form shown in Fig. 9. Initially, as the indentation depth is increased, the polymer network, with its fixed charge and associated counterion condensation [78] is compressed closer to the sensing area. As the solute has not had time to diffuse away, the bioimpedance sensor detects a local increase in conductivity. As the solvent flows radially under the combined influence of high hydraulic pressure and chemical potential, the dilation becomes increasingly negative [70] causing the water volume fraction and diffusivity of the solute to decrease over time resulting in a corresponding increase in resistivity, even though the indentation depth is kept constant. The same phenomena can be seen during the large strain indentation experiments (see Fig. 12). The difference here is that the indentation has taken sufficient time that the flow has become significant whilst the indentation depth is still increasing, hence the transition from decreasing to increasing resistivity at the $\sim 20$ second mark. It is also very likely that due to the high level of deformation in the large strain indentation experiments that the increase in resistivity is compounded by water loss through the surface of the hydrogel through

\begin{tabular}{|c|c|c|c|}
\hline Ion & Valence & $\begin{array}{c}\text { Concentration } \\
(\mathrm{mmol} / \mathrm{L})\end{array}$ & $\begin{array}{l}\text { Diffusivity } \\
\left(\times 10^{-9} \mathrm{~m}^{2} / \mathrm{s}\right)\end{array}$ \\
\hline $\mathrm{Na}^{+}$ & 1 & 54.76 & 1.334 \\
\hline $\mathrm{K}^{+}$ & 1 & 2.68 & 1.957 \\
\hline $\mathrm{SO}_{4}{ }^{2-}$ & 2 & 0.41 & 1.065 \\
\hline $\mathrm{Ca}^{2+}$ & 2 & 0.90 & 0.792 \\
\hline $\mathrm{Cl}^{-}$ & 1 & 59.24 & 2.032 \\
\hline $\mathrm{Mg}^{2+}$ & 2 & 0.41 & 0.706 \\
\hline
\end{tabular}
syneresis.

Table 3: The properties of the free ions assumed to be in the alginate/S-DMEM hydrogel. Composition due to $50 \%$ S-DMEM as given in [78]. Diffusivities from [79].

\section{Permittivity of tissue}

The permittivity measured in Figs. 10 and 13 is of interest as it is so high. A recent study on dehydrated $\mathrm{Ca}^{2+}$ crosslinked alginate [81] suggests a relative permittivity of c.a. 10 at a frequency of $1 \mathrm{kHz}$ for the polymer network without added salts, with pure water being known to be $\sim 80$. Other studies on swollen alginate gels [82] have noted that the permittivity is strongly dependent on alginate concentration and frequency. In particular, it was observed that the relative permittivity of alginate gels can vary by c.a. five orders of magnitude over a frequency range of $10 \mathrm{mHz}$ to $10 \mathrm{kHz}$. This observation suggests a deviation away from the commonly assumed "double-layer" capacitance effect caused by the distribution of ions close to the electrode surface and frequently modelled using the Gouy-ChapmanStern model and represented by an additional resistor and capacitor in parallel between the electrodes and the bulk material [83, 84]. Instead, it was hypothesised [82] that the layer close to the electrodes may consist of adsorbed alginate molecules. This results in ion-dipole interactions and a dispersive capacitive effect occurring at the electrode interface. These dipoles are not just due to the orientation of the fixed charge about the chain axis, but also due to the segmental motion of the local free alginate chains and the polarization of the condensed counterions [85]. These phenomena are dependent on the alginate concentration, crosslinking density, and solute concentration in a complex manner and are the focus of future work.

Frequently, very high permittivities for hydrogels are only observed at frequencies lower than used in this study [82]. However, the added S-DMEM and associated salts may also contribute to the permittivity by causing a space charge polarization effect $[84,86]$. The free ions in the solvent generally have different diffusivities and are driven at different velocities by the alternating electric field caused by the bioimpedance sensor. This results in a transient separation of cations and anions and hence a frequency dependent polarization due to ions in the bulk of the material. The exact interplay of these factors is currently unknown, but could add up to result in the high permittivities observed in Figs. 10 and 13. In these figures, the permittivities are observed to decrease relatively linearly with increasing indentation depth before continuing to decrease while the indentation depth is kept constant. It is likely that the same factors that caused the transient resistivity are also responsible for the observed transient permittivity. The initial compression and subsequent decrease of the dilation may have also caused a restriction of the polymer network, reducing orientation polarizations, as well as the reduction of the diffusivities of the solute and related subdued ionic polarizations at both the electrode interface and in the bulk, manifested as a reduction of permittivity as a function of time. 


\section{Effect of fibroblast encapsulation}

The phenomena described above also explains the general trends seen during the cellular experiments (see Figs. 14 to 19) except for some key differences. It has already been discussed that the presence of the encapsulated fibroblasts in the alginate/S-DMEM hydrogel has not affected the rheology significantly, despite the cells having their own transient properties $[87,88]$. This was attributed to the fibroblasts not attaching to the alginate matrix. This is important because fibroblasts are anchorage dependent [89] which means being attached to the extracellular matrix affects many cellular functions including migration, proliferation, differentiation, and apoptosis [90] as well as mechanotransduction.

It is well known that fibroblasts are mechanosensitive [9] and that the forces exerted on fibroblasts can affect cell mobility, gene regulation [91] and promote remodelling of the extracellular matrix [92]. In in vivo conditions, the cellmatrix adhesions discussed above are the main components for transducing mechanical forces from the outside to the inside of the cell. Two main components have been implicated in the transduction from mechanical to electrochemical signals: ion channels and integrins $[93,94]$. It has been hypothesised that a fibroblast is only able to sense mechanical stress at its external surface if it maintains a certain amount of resistance by internal cytoskeletal tension [91], in accordance with the tensegrity paradigm [95]. One reason that was suggested [96], was that integrins, whilst acting as a physical link between the extracellular matrix and the cytoskeleton, acts as a kind of strain gauge and therefore cytoskeleton tension is needed to transmit stress to the internal cell components. As suggested, stretch sensitive cation channels might also participate in mechanical to electrochemical signal transduction. In excitable cells, the cation channels may be directly attached to the extracellular matrix and hence be explicitly involved in mechanotransduction [97] and translate mechanical forces and deformations into electrochemical signals such as changes in intracellular calcium concentration. Such phenomenon can also occur in non-excitable cells, such as fibroblasts, as well [94, 98]. There is evidence to suggest that the cation channels in fibroblasts can be activated by mechanical stress without the channels being physically connected to the extracellular matrix or other cells. For instance, Wright et al. [99] noted that applied hydrostatic pressure on human skin fibroblasts in non-confluent monolayer cultures exhibited cation channel activation and hyperpolarization of the transmembrane potential. It has also been observed that fluid shear stress can affect fibroblast behaviour, particularly in vivo in response to chemical or mechanical injury [100]. However, it was noted that 3D studies on mechanotransduction mechanisms in fibroblasts are limited by the permeability and structure of the extracellular matrix which prevent close scrutiny [100].
Given we have assumed that fibroblasts do not attach to the alginate polymer network and so integrins are unlikely to be a source of mechanotransduction, we can hypothesise that the 'kinks' in the resistivity and permittivity data for low strain indentation of cellular hydrogel (Figs. 15 and 16) are due to intracellular calcium concentration due to activation of the cation channels due to the hydraulic pressure applied during indentation. The sudden locally increased concentration of calcium ions may have led to an increase in the conductivity above the base trends as seen in Fig. 15 as well as additional or enhanced charge space polarizations increasing the permittivity as seen in Fig. 16. To the authors' knowledge, similar observations in comparable systems has not been observed before. Further tests are required before firm conclusions can be made.

It can be seen that the shape and magnitude of the response appears to a function of the indentation depth (see Figs. 15 and 16). While there is a strong and almost immediate change in both the resistivity and permittivity in the cellular hydrogel for an indentation depth of $20 \mu \mathrm{m}$, the change occurs later, after a time period of the order of minutes of constant indentation depth, for the experiments of higher indentation depth. Also, the effect appears to get weaker as the indentation depth increases. Indeed, there is very little change observed at all in the resistivity of the cellular hydrogel during the large strain indentation experiments (see Fig. 18) and only in the $250 \mu \mathrm{m}$ indentation experiment is a change in the relative permittivity seen. The reasons for this are not known. It is possible that, as it is known that ionically cross-linked alginates lose mechanical properties over time in vitro, presumably due to an outward flux of cross-linking ions into the surrounding medium [101], at large strains the degradation of the cross-links in the alginate is being accelerated and that the calcium ions released are affecting the cell behaviour [102-104].

The oscillation observed in the resistivity as shown in Fig. 15 are reminiscent of typical action potential including a depolarization, repolarization and refractory stage [105]. The delay in the response may be due to the temporal dynamics of $\mathrm{Ca}^{2+}$ signalling events in fibroblasts which involve a number of complex processes [106]. Alternatively, it may be due to the inherent viscoelasticity of the fibroblasts in part associated with the actindependent traction forces that develop in response to applied loads which invoke changes to the cytoskeleton over time scales of minutes $[87,107]$. These factors are also the focus of future studies.

\section{Conclusion}

The use of impedance sensors to monitor the effective resistivity and permittivity of artificial tissues has been successfully demonstrated. Alginate hydrogel containing encapsulated 3T3 fibroblasts was used as an artificial skin analogue, and was kept viable through the use of a bespoke 
microfluidic system. As compressive normal loads were applied to the artificial skin via spherical indentation, the impedance response was monitored in real time at a fixed single frequency. Cellular and acellular hydrogels produced different transient impedance responses upon the application of identical compressive normal loads. The discrepancies in the observed resistivities and permittivities were interpreted as transient changes in ion concentrations due to mechanotransduction effects induced in the encapsulated fibroblast population.

\section{Acknowledgments}

This work was supported by the European Union under the FP7 programme (NANOBIOTOUCH Project: FP7-NMP228844). The Z030 mechanical tester (Zwick/Roell, UK) used in this research was obtained, through Birmingham Science City: Innovative Uses for Advanced Materials in the Modern World (West Midlands Centre for Advanced Materials Project 2), with support from Advantage West Midlands (AWM) and part funded by the European Regional Development Fund (ERDF).

\section{References}

1. Orr AW, Helmke BP, Blackman BR, Schwartz MA. Mechanisms of mechanotransduction. Developmental cell, 2006:10(1):11-20.

http://dx.doi.org/10.1016/j.devcel.2005.12.006

2. Chiquet M, Gelman L, Lutz R, Maier S. From mechanotransduction to extracellular matrix gene expression in fibroblasts. Biochimica et Biophysica Acta (BBA)Molecular Cell Research, 2009:1793(5):911-920.

3. Sukharev S, Sachs F. Molecular force transduction by ion channels-diversity and unifying principles. Journal of cell science, 2012:125(13):3075-3083.

http://dx.doi.org/10.1242/jcs.092353

4. Burgess PT, Perl, ER. Cutaneous mechanoreceptors and nociceptors. In Somatosensory system. Springer Berlin Heidelberg; 1973. p. 29-78.

http://dx.doi.org/10.1007/978-3-642-65438-1_3

5. Brownell WE, Bader CR, Bertrand D, de Ribaupierre Y. Evoked mechanical responses of isolated cochlear outer hair cells. Science, 1985:227(4683):194-196.

http://dx.doi.org/10.1126/science.3966153

6. Moss ML. The functional matrix hypothesis revisited. 1. The role of mechanotransduction. American journal of orthodontics and dentofacial orthopedics, 1997:112(1):8-11. http://dx.doi.org/10.1016/S0889-5406(97)70267-1

7. Numaguchi K, Eguchi S, Yamakawa T, Motley ED, Inagami T. Mechanotransduction of rat aortic vascular smooth muscle cells requires RhoA and intact actin filaments. Circulation Research, 1991:85(1):5-11. http://dx.doi.org/10.1161/01.RES.85.1.5
8. Hahn C, Schwartz MA. Mechanotransduction in vascular physiology and atherogenesis. Nature Reviews Molecular Cell Biology, 2009:10(1):53-62. http://dx.doi.org/10.1038/nrm2596

9. Chiquet M, Renedo AS, Huber F, Flück M. How do fibroblasts translate mechanical signals into changes in extracellular matrix production? Matrix biology, 2003:22(1):73-80. http://dx.doi.org/10.1016/S0945-053X(03)00004-0

10. Langevin HM, Bouffard NA, Badger GJ, Churchill DL, Howe AK. Subcutaneous tissue fibroblast cytoskeletal remodeling induced by acupuncture: Evidence for a mechanotransductionbased mechanism. Journal of cellular physiology, 2006:207(3):767-774. http://dx.doi.org/10.1002/jcp.20623

11. Schwarz US, Gardel ML. United we stand-integrating the actin cytoskeleton and cell-matrix adhesions in cellular mechanotransduction. Journal of cell science, 2012:125(13):3051-3060. http://dx.doi.org/10.1242/jcs.093716

12. Zhang H. Labouesse M. Signalling through mechanical inputs-a coordinated process. Journal of cell science, 2012:125(13):3039-3049. http://dx.doi.org/10.1242/jcs.093666

13. Martinac B. Mechanosensitive ion channels: molecules of mechanotransduction. Journal of cell science, 2004:117(12):2449-2460. http://dx.doi.org/10.1242/jcs.01232

14. Kandel ER, Schwartz JH, Jessell TM. (Eds.). Principles of neural science Vol. 4, New York: McGraw-Hill; 2000.

15. Neef K, Choi YH, Perumal Srinivasan S, Treskes P, Cowan DB, Stamm C, Wahlers T. Mechanical preconditioning enables electrophysiologic coupling of skeletal myoblast cells to myocardium. The Journal of thoracic and cardiovascular surgery, 2012:144(5):1176-1184. http://dx.doi.org/10.1016/j.jtcvs.2012.07.036

16. Han A. Microfabricated Multi-Analysis System for Electrophysiological Studies of Single Cells. PhD Thesis, Georgia Institute of Technology, 2005.

17. Abramochkin DV, Lozinsky IT, Kamkin A. Influence of mechanical stress on fibroblast-myocyte interactions in mammalian heart. Journal of molecular and cellular cardiology. 2014:70:27-36. http://dx.doi.org/10.1016/j.yjmcc.2013.12.020

18. French AS. Mechanotransduction. Annual review of physiology, 1992:54(1):135-152. http://dx.doi.org/10.1146/annurev.ph.54.030192.001031

19. Davies PF, Barbee KA, Volin MV, Robotewskyj A, Chen J, Joseph L, Barakat AI. Spatial relationships in early signaling events of flow-mediated endothelial mechanotransduction. Annual Review of Physiology, 1997:59(1):527-549. http://dx.doi.org/10.1146/annurev.physiol.59.1.527

20. Dalby MJ, Riehle MO, Sutherland DS, Agheli H, Curtis AS. Use of nanotopography to study mechanotransduction in fibroblasts-methods and perspectives. European journal of cell biology, 2004:83(4):159-169. http://dx.doi.org/10.1078/0171-9335-00369

21. Martinez E, Engel E, Planell JA, Samitier J. Effects of artificial micro-and nano-structured surfaces on cell behaviour. 
Annals of Anatomy-Anatomischer Anzeiger, 2009:191(1):126-135.

http://dx.doi.org/10.1016/j.aanat.2008.05.006

22. Ross TD, Coon BG, Yun S, Baeyens N, Tanaka K, Ouyang, M, Schwartz MA. Integrins in mechanotransduction. Current opinion in cell biology, 2013:25(5):613-618. http://dx.doi.org/10.1016/j.ceb.2013.05.006

23. Geiger B, Bershadsky A, Pankov R, Yamada KM. Transmembrane crosstalk between the extracellular matrix and the cytoskeleton. Nature Reviews Molecular Cell Biology, 2001:2(11):793-805. http://dx.doi.org/10.1038/35099066

24. Baker BM, Chen CS. Deconstructing the third dimension-how 3D culture microenvironments alter cellular cues. Journal of cell science, 2012:125(13):3015-3024. http://dx.doi.org/10.1242/jcs.079509

25. Katsumi A, Orr AW, Tzima E, Schwartz MA. Integrins in mechanotransduction. Journal of Biological Chemistry, 2004:279(13):12001-12004. http://dx.doi.org/10.1074/jbc.R300038200

26. Chen CS, Tan J, Tien J. Mechanotransduction at cell-matrix and cell-cell contacts. Annu. Rev. Biomed. Eng., 2004:6:275302.

http://dx.doi.org/10.1146/annurev.bioeng.6.040803.140040

27. Wang JHC, Thampatty BP, Lin JS, Im HJ. Mechanoregulation of gene expression in fibroblasts. Gene, 2007:391(1):1-15. http://dx.doi.org/10.1016/j.gene.2007.01.014

28. Benson K, Cramer S, Galla HJ. Impedance-based cell monitoring: barrier properties and beyond. Fluids and barriers of the CNS, 2013:10(5).

29. Qiu Y, Liao R, Zhang X. Real-time monitoring primary cardiomyocyte adhesion based on electrochemical impedance spectroscopy and electrical cell-substrate impedance sensing. Analytical chemistry, 2008:80(4):990-996. http://dx.doi.org/10.1021/ac701745c

30. Dodde RE, Bull JL, Shih, AJ. Bioimpedance of soft tissue under compression. Physiological measurement, 2012:33(6):1095. http://dx.doi.org/10.1088/0967$3334 / 33 / 6 / 1095$

31. Belmont B, Dodde RE, Shih AJ. Impedance of tissuemimicking phantom material under compression. Journal of Electrical Bioimpedance, 2013:4(1):2-12. http://dx.doi.org/10.5617/jeb.443

32. Nam JH, Chen PC, Lu Z, Luo H, Ge R, Lin W. Force control for mechanoinduction of impedance variation in cellular organisms. Journal of Micromechanics and Microengineering, 2010:20(2):025003.

http://dx.doi.org/10.1088/0960-1317/20/2/025003

33. Miano G, Maffucci A. Transmission lines and lumped circuits: fundamentals and applications. Academic Press; 2001.

34. Xiang Y. The electrostatic capacitance of an inclined plate capacitor, Journal of Electrostatics, 2006:64:29-34. http://dx.doi.org/10.1016/j.elstat.2005.05.002
35. Hong J, Yoon DS, Kim SK, Kim TS, Kim S, Pak EY, No K, $\mathrm{AC}$ frequency characteristics of coplanar impedance sensors as design parameters, Lab on a Chip, 2005:5:270-279. http://dx.doi.org/10.1039/b410325d

36. Gevorgian S, Berg H. Line capacitance and impedance of coplanar-strip waveguides on substrates with multiple dielectric layers, 31st European Microwave Conference (London); 2001:1-4.

37. Hunt NC, An alginate hydrogel matrix for the localised delivery of a fibroblast/keratinocyte co-culture to expedite wound healing, PhD Thesis, University of Birmingham, 2010

38. Kaklamani G, Cheneler D, Grover LM, Adams MJ, Bowen J. Mechanical properties of alginate hydrogels manufactured using external gelation. Journal of the mechanical behavior of biomedical materials, 2014:36:135-142. http://dx.doi.org/10.1016/j.jmbbm.2014.04.013

39. Lin DC, Shreiber DI, Dimitriadis EK, Horkay F. Spherical indentation of soft matter beyond the Hertzian regime: numerical and experimental validation of hyperelastic models. Biomechanics and modeling in mechanobiology, 2009:8(5):345-358. http://dx.doi.org/10.1007/s10237-008-0139-9

40. Cheneler D, Mehrban N, Bowen J. Spherical indentation analysis of stress relaxation for thin film viscoelastic materials. Rheologica Acta, 2013:52(7):695-706. http://dx.doi.org/10.1007/s00397-013-0707-5

41. Coleman TF, Y Li. An Interior, Trust Region Approach for Nonlinear Minimization Subject to Bounds, SIAM Journal on Optimization, 1996:6:418-445. http://dx.doi.org/10.1137/0806023

42. Demirel MC, So E, Ritty TM, Naidu SH, Lakhtakia A. Fibroblast Cell Attachment and Growth on Nanoengineered Sculptured Thin Films, J Biomed Mater Res B Appl Biomater., 2007:81(1):219-223. http://dx.doi.org/10.1002/jbm.b.30656

43. Tandon GP, Weng GJ. The effect of aspect ratio of inclusions on the elastic properties of unidirectionally aligned composites. Polymer composites 1984:5(4):327-333. http://dx.doi.org/10.1002/pc.750050413

44. Cukierman E, Pankov R, Stevens DR, Yamada KM. Taking cell-matrix adhesions to the third dimension. Science, 2001:294(5547):1708-1712. http://dx.doi.org/10.1126/science.1064829

45. Zamir E, Katz BZ, Aota SI, Yamada KM, Geiger B, Kam Z. Molecular diversity of cell-matrix adhesions. Journal of cell science, 1999:112(11):1655-1669.

46. Rowley JA., Madlambayan G, Mooney DJ. Alginate hydrogels as synthetic extracellular matrix materials. Biomaterials, 1991:20(1):45-53. http://dx.doi.org/10.1016/S0142-9612(98)00107-0

47. Smetana Jr, K. Cell biology of hydrogels. Biomaterials, 1993:14(14):1046-1050. http://dx.doi.org/10.1016/0142-9612(93)90203-E 
48. Harunaga JS, Yamada KM. Cell-matrix adhesions in 3D. Matrix Biology, 2011:30(7):363-368. http://dx.doi.org/10.1016/j.matbio.2011.06.001

49. Shapiro L, Cohen S. Novel alginate sponges for cell culture and transplantation. Biomaterials, 1997:18(8):583-590. http://dx.doi.org/10.1016/S0142-9612(96)00181-0

50. Zhang J, Daubert CR, Foegeding EA, A proposed strainhardening mechanism for alginate gels, Journal of Food Engineering, 2007:80(1):157-165. http://dx.doi.org/10.1016/j.jfoodeng.2006.04.057

51. Smidsrød O. Molecular-basis for some physical-properties of alginates in gel state, Journal of Chemical Society: Faraday Transactions, 1975:57:263-272.

52. Clark AH, Ross-Murphy SB. Structure and mechanical properties of biopolymer gels, Advances in Polymer Science, 1987:83:59-191. http://dx.doi.org/10.1007/BFb0023332

53. Blatz PJ, Sharda SC, Tschoegl NW. Strain energy function for rubberlike materials based on a generalized measure of strain, Transactions of the Society of Rheology, 1974:18(1):145-161. http://dx.doi.org/10.1122/1.549353

54. Doi M, Kuzuu NY, Non-linear elasticity of rodlike macromolecules in condensed state, Journal of Polymer Science: Polymer Physics Edition, 1980:18:409-419. http://dx.doi.org/10.1002/pol.1980.180180301

55. Shapiro JM, Oyen ML. Viscoelastic analysis of singlecomponent and composite PEG and alginate hydrogels. Acta Mechanica Sinica, 2014:30(1):7-14. http://dx.doi.org/10.1007/s10409-014-0025-x

56. Olderøy MØ, Xie M, Andreassen JP, Strand BL, Zhang Z, Sikorski P. Viscoelastic properties of mineralized alginate hydrogel beads. Journal of Materials Science: Materials in Medicine, 2012:23(7):1619-1627. http://dx.doi.org/10.1007/s10856-012-4655-x

57. Andrews JW, Bowen J, Cheneler D. Optimised determination of viscoelastic properties using compliant measurement systems. Soft Matter, 2013:9(23):5581-5593. http://dx.doi.org/10.1039/c3sm50706h

58. Lee EH, Radok JRM. The contact problem for viscoelastic bodies. Journal of Applied Mechanics, 1960:27(3):438-444. http://dx.doi.org/10.1115/1.3644020

59. Lai WM, Hou JS, Mow VC. A triphasic theory for the swelling and deformation behaviors of articular cartilage. Journal of biomechanical engineering, 1991:113(3):245-258. http://dx.doi.org/10.1115/1.2894880

60. Huyghe JM, Janssen JD. Quadriphasic mechanics of swelling incompressible porous media. International Journal of Engineering Science, 1997:35(8):793-802. http://dx.doi.org/10.1016/S0020-7225(96)00119-X

61. Hong W, Zhao X, Zhou J, Suo Z. A theory of coupled diffusion and large deformation in polymeric gels. Journal of the Mechanics and Physics of Solids, 2008:56(5):1779-1793. http://dx.doi.org/10.1016/j.jmps.2007.11.010
62. Feng L, Jia Y, Chen X, Li X, An L. A multiphasic model for the volume change of polyelectrolyte hydrogels. The Journal of chemical physics, 2010:133(11):114904. http://dx.doi.org/10.1063/1.3484236

63. Chester SA. A constitutive model for coupled fluid permeation and large viscoelastic deformation in polymeric gels. Soft Matter, 2012:8(31):8223-8233. http://dx.doi.org/10.1039/c2sm25372k

64. Wang X, Hong W. A visco-poroelastic theory for polymeric gels. Proceedings of the Royal Society A: Mathematical, Physical and Engineering Science, 2012:468(2148):38243841.

65. Drozdov AD, Christiansen J. Stress-strain relations for hydrogels under multiaxial deformation. International Journal of Solids and Structures, 2013:50(22):3570-3585. http://dx.doi.org/10.1016/j.ijsolstr.2013.06.023

66. Ateshian GA, Chahine NO, Basalo IM, Hung CT. The correspondence between equilibrium biphasic and triphasic material properties in mixture models of articular cartilage. Journal of biomechanics, 2004:37(3):391-400. http://dx.doi.org/10.1016/S0021-9290(03)00252-5

67. Hoang SK, Abousleiman YN. Correspondence principle between anisotropic poroviscoelasticity and poroelasticity using micromechanics and application to compression of orthotropic rectangular strips. Journal of Applied Physics, 2012:112(4):044907. http://dx.doi.org/10.1063/1.4748293

68. Huyghe JM, Malakpoor K, Wilson W. On the thermodynamical admissibility of the triphasic theory of charged hydrated tissues. Journal of biomechanical engineering, 2009:131(4):044504. http://dx.doi.org/10.1115/1.3049531

69. Aslani P, Kennedy RA. Studies on diffusion in alginate gels. I. Effect of cross-linking with calcium or zinc ions on diffusion of acetaminophen. Journal of controlled release, 1996:42(1):75-82. http://dx.doi.org/10.1016/0168-3659(96)01369-7

70. Lu XL, Wan LQ, Guo X, Mow VC. A linearized formulation of triphasic mixture theory for articular cartilage, and its application to indentation analysis. Journal of biomechanics, 2010:43(4):673-679. http://dx.doi.org/10.1016/j.jbiomech.2009.10.026

71. Duan Z, An Y, Zhang J, Jiang H. The effect of large deformation and material nonlinearity on gel indentation. Acta Mechanica Sinica, 2012:28(4),1058-1067. http://dx.doi.org/10.1007/s10409-012-0122-7

72. Wilson W, van Donkelaar CC, Huyghe JM. A comparison between mechano-electrochemical and biphasic swelling theories for soft hydrated tissues. Journal of biomechanical engineering, 2005:127(1):158-165. http://dx.doi.org/10.1115/1.1835361

73. Jackson AR, Yuan TY, Huang CY, Gu WY. A Conductivity Approach to Measuring Fixed Charge Density in Intervertebral Disc Tissue. Annals of biomedical engineering, 2009:37(12):2566-2573. http://dx.doi.org/10.1007/s10439-009-9792-0 
74. Amsden B. Solute diffusion within hydrogels. Mechanisms and models. Macromolecules, 1998:31(23):8382-8395. http://dx.doi.org/10.1021/ma980765f

75. Gu WY, Yao H, Vega AL, Flagler D. Diffusivity of ions in agarose gels and intervertebral disc: effect of porosity. Annals of biomedical engineering, 2004:32(12):1710-1717. http://dx.doi.org/10.1007/s10439-004-7823-4

76. Gu WY, Yao H, Huang CY, Cheung HS. New insight into deformation-dependent hydraulic permeability of gels and cartilage, and dynamic behavior of agarose gels in confined compression. Journal of biomechanics, 2003:36(4):593-598. http://dx.doi.org/10.1016/S0021-9290(02)00437-2

77. Lai WM, Mow VC, Roth V. Effects of nonlinear straindependent permeability and rate of compression on the stress behavior of articular cartilage. Journal of biomechanical engineering, 1981:103(2):61-66. http://dx.doi.org/10.1115/1.3138261

78. O'Shaughnessy B, Yang Q. Manning-Oosawa counterion condensation. Physical review letters, 2005:94(4):048302. http://dx.doi.org/10.1103/PhysRevLett.94.048302

79. Sigma-Aldrich [Internet]. Dulbecco's Modified Eagle's Medium Formulation [Updated cited 2014 April 14]. Available from: http://www.sigmaaldrich.com/lifescience/cell-culture/learning-center/mediaformulations/dme.html

80. Perry RH, Green DW, Maloney, JO. Perry's chemical engineer's handbook. McGraw-Hill Book; 1984.

81. Bekin S, Sarmad S, Gürkan K, Yenici G, Keçeli G, Gürdağ G. Dielectric, thermal, and swelling properties of calcium ioncrosslinked sodium alginate film. Polymer Engineering \& Science. 2013

82. Binns JS, Craig DQM, Hill RM, Davies MC, Melia CD, Newton JM, Dielectric characterisation of sodium alginate gels. Journal of Materials Chemistry, 1992:2(5):545-549. http://dx.doi.org/10.1039/jm9920200545

83. Lin SP, Kyriakides TR, Chen JJJ. On-line observation of cell growth in a three-dimensional matrix on surface-modified microelectrode arrays. Biomaterials, 2009:30(17):3110-3117. http://dx.doi.org/10.1016/j.biomaterials.2009.03.017

84. Sawada A. Tarumi K, Naemura S. Effects of electric double layer and space charge polarization by plural kinds of ions on complex dielectric constant of liquid crystal materials. Japanese journal of applied physics, 1991:38(3R):1418.

85. Bordi F, Cametti C, Colby RH. Dielectric spectroscopy and conductivity of polyelectrolyte solutions. Journal of Physics: Condensed Matter, 2004:16(49):R1423. http://dx.doi.org/10.1088/0953-8984/16/49/R01

86. Sawada A. Internal electric fields of electrolytic solutions induced by space-charge polarization. Journal of applied physics, 2006:100(7):074103. http://dx.doi.org/10.1063/1.2355449

87. Thoumine O, Ott A. Time scale dependent viscoelastic and contractile regimes in fibroblasts probed by microplate manipulation. Journal of cell science, 1997:110(17):21092116.

88. Park S, Koch D, Cardenas R, Käs J, Shih CK. Cell motility and local viscoelasticity of fibroblasts. Biophysical journal, 2005:89(6):4330-4342. http://dx.doi.org/10.1529/biophysj.104.053462

89. Ruoslahti E, Reed JC. Anchorage dependence, integrins, and apoptosis. Cell, 1994:77(4):477-478. http://dx.doi.org/10.1016/0092-8674(94)90209-7

90. Ingber DE. Mechanochemical switching between growth and differentiation by extracellular matrix, In: Lanza RP, Langer R, Chick WL, editors. Principles of tissue engineering. Austin, TX: R.G. Landes Company, 1997:89-100.

91. Chiquet M, Tunc-Civelek V, Sarasa-Renedo A. Gene regulation by mechanotransduction in fibroblasts. Applied Physiology, Nutrition, and Metabolism, 2007:32(5):967-973. http://dx.doi.org/10.1139/H07-053

92. Ko KS, McCulloch CA. Intercellular mechanotransduction: cellular circuits that coordinate tissue responses to mechanical loading. Biochemical and biophysical research communications, 2001:285(5):1077-1083. http://dx.doi.org/10.1006/bbrc.2001.5177

93. Shyy JY, Chien S. Role of integrins in cellular responses to mechanical stress and adhesion. Current opinion in cell biology, 1997:9(5):707-713. http://dx.doi.org/10.1016/S0955-0674(97)80125-1

94. Van Den Brink GR, Bloemers SM, Van Den Blink B, Tertoolen LG, Van Deventer SJ, Peppelenbosch MP. Study of calcium signaling in non-excitable cells. Microscopy research and technique, 1999:46(6):418-433.

http://dx.doi.org/10.1002/(SICI)1097-

0029(19990915)46:6<418::AID-JEMT9>3.0.CO;2-0

95. Ingber DE. Tensegrity: the architectural basis of cellular mechanotransduction. Annual review of physiology, 1997:59(1):575-599.

http://dx.doi.org/10.1146/annurev.physiol.59.1.575

96. Choquet D, Felsenfeld DP, Sheetz MP. Extracellular matrix rigidity causes strengthening of integrin-cytoskeleton linkages. Cell, 1997:88(1):39-48. http://dx.doi.org/10.1016/S0092-8674(00)81856-5

97. Walker RG, Willingham AT, Zuker CS. A Drosophila mechanosensory transduction channel. Science, 2000:287(5461):2229-2234. http://dx.doi.org/10.1126/science.287.5461.2229

98. Iqbal J, Zaidi M. Molecular regulation of mechanotransduction. Biochemical and biophysical research communications, 2005:328(3):751-755. http://dx.doi.org/10.1016/j.bbrc.2004.12.087

99. Wright MO, Stockwell RA, Nuki G. Response of plasma membrane to applied hydrostatic pressure in chondrocytes and fibroblasts. Connective tissue research, 1992:28(1-2):49-70. http://dx.doi.org/10.3109/03008209209014227 
100. Shi ZD, Tarbell JM. Fluid flow mechanotransduction in vascular smooth muscle cells and fibroblasts. Annals of biomedical engineering, 2011:39(6):1608-1619. http://dx.doi.org/10.1007/s10439-011-0309-2

101. Shoichet MS, Li RH, White ML, Winn SR. Stability of hydrogels used in cell encapsulation: An in vitro comparison of alginate and agarose. Biotechnology and bioengineering, 2006:50(4):374-381. http://dx.doi.org/10.1002/(SICI)10970290(19960520)50:4<374::AID-BIT4>3.0.CO;2-I

102. Ko KS, Arora PD, McCulloch CA. Cadherins mediate intercellular mechanical signaling in fibroblasts by activation of stretch-sensitive calcium-permeable channels. Journal of Biological Chemistry, 2001:276(38):35967-35977. http://dx.doi.org/10.1074/jbc.M104106200

103. Harootunian AT, Kao JP, Paranjape S, Tsien RY. Generation of calcium oscillations in fibroblasts by positive feedback between calcium and IP3. Science, 1991:251(4989), 75-78. http://dx.doi.org/10.1126/science.1986413
104. McNeil SE, Hobson SA, Nipper V, Rodland, KD. Functional calcium-sensing receptors in rat fibroblasts are required for activation of SRC kinase and mitogen-activated protein kinase in response to extracellular calcium. Journal of Biological Chemistry, 1998:273(2):1114-1120. http://dx.doi.org/10.1074/jbc.273.2.1114

105. De Roos AD, Willems PH, Van Zoelen EJ, Theuvenet AP. Synchronized $\mathrm{Ca} 2+$ signaling by intercellular propagation of $\mathrm{Ca} 2+$ action potentials in NRK fibroblasts. American Journal of Physiology-Cell Physiology, 1997:273(6):C1900-C1907.

106. Breitwieser GE. Extracellular calcium as an integrator of tissue function. The international journal of biochemistry \& cell biology, 2008:40(8):1467-1480. http://dx.doi.org/10.1016/j.biocel.2008.01.019

107. DuFort CC, Paszek MJ, Weaver, VM. Balancing forces: architectural control of mechanotransduction. Nature Reviews: Molecular cell biology, 2011:12(5):308-319. http://dx.doi.org/10.1038/nrm3112 